\title{
CONOCIMIENTOS ESPECIALES EN LA DOGMÁTICA JURÍDICO-PENAL Y TEORÍA DE LAS CIENCIAS
}

\author{
Javier Wilenmann Von Bernath*
}

\begin{abstract}
1. Introducción; 2. Esquema conceptual; 3. El programa normativista radical de Jakobs: a) Núcleo firme, b) El cinturón protector; 4. El programa funcionalista-político criminal: a) El núcleo firme, b) El cinturón protector; 5. Conocimientos especiales: a) Cuestiones generales, b) Los conocimientos especiales en la prognosis-objetivo posterior, c) Normativización de la persona, del observador, y exclusión de los conocimientos especiales.
\end{abstract}

\section{Introducción}

El objeto de este artículo es presentar una reconstrucción descriptiva de una polémica dogmático-penal ocupando los esquemas conceptuales de reconstrucción de polémicas científicas construidos por la teoría de las ciencias. Con ello, se pretende usar estas categorías con un fin puramente instrumental (ver estético) en relación con la explicación de las diferencias en ciertas conclusiones particulares en dos programas de investigación dogmática penal. Ello podría tener ciertamente un rol esclarecedor conceptual y difícilmente podría jugar, en cambio, un rol relevante en la adjudicación de la polémica.

La teoría de las ciencias, en términos de Lakatos, tiene por función esencial servir a una reconstrucción racional histórica de la ciencia pura, esto es a una reconstrucción de historia interna. La fórmula de Lakatos requiere una explicación. Lo que ella sugiere es que todo análisis de teorías de las ciencias funciona necesariamente en forma retrospectiva y tomando en cuenta la evolución temporal, renunciando con ello a la posibilidad de adjudicación contemporánea, pero manteniendo la pretensión de evaluación de la racionalidad de las teorías pasadas. Su objeto de análisis es siempre, en algún sentido, "historia", pero pese a ello y pese a la alta probabilidad de tener un objeto de análisis obsoleto, no por ello deja de ser racional. La diferenciación de la historia externa permite satisfacer la reconstrucción del cambio sin renunciar, como Kuhn, a la pretensión de racionalidad histórica de las ciencias.

Racionalidad entendida, con algún grado de sofisticación moderna, como correspondencia con la realidad o, en términos menos metafísicos, como relación posible con la experiencia, sólo se da en el ámbito científico puro. La referencia a la experiencia como contraste falseador o confirmador y al principio de inducción como argumento puente, es lo que históricamente han asumido las ciencias naturales como su forma particular de racionalidad. El peso pragmático de esta

\footnotetext{
* Profesor de Derecho Penal de la Universidad Adolfo Ibáñez; email: javier.wilenmann@uai.cl
} 
Willenmann - Conocimientos especiales en la dogmática...

forma racionalidad siempre ha sido tan fuerte, que ha tendido a la vez a atraer al resto y a menospreciar cualquier otra forma de racionalidad. ${ }^{1}$

En cambio, lo que sea la racionalidad dogmática o, en términos generales la racionalidad jurídica, siempre ha sido mucho más complejo de dilucidar. En parte, la racionalidad de la dogmática puede ser explicada sin muchos problemas no ya como una cuestión de racionalidad del saber, sino como una cuestión de racionalidad de la acción, es decir, en relación con su función o utilidad social. ${ }^{2}$ Así por ejemplo, Roxin caracteriza la racionalidad de la dogmática jurídico penal como una "posibilitación de una aplicación segura y calculable del Derecho Penal", como un "presupuesto de una aplicación uniforme y diferenciada del Derecho", y como una condición del "pensamiento sistemático". ${ }^{3}$ Para Roxin, las pretensiones de la Teoría del Delito son análogas a las pretensiones de uniformidad y de predicción de resultados de acciones externas que tienen las ciencias naturales, lo que se justificaría por la violencia del Derecho Penal: no puede ser arbitrario, por lo que no puede ser aleatorio. Con ello, la dogmática penal pretendería llevar a cabo una construcción argumentativa que permita predecir con cierta precisión las consecuencias de ciertas conductas, de forma de contribuir al ejercicio de la libertad de los ciudadanos. Así, su pretensión material como actividad sería análoga a la ciencia en sus pretensiones formales. Pese a que una construcción de este tipo, desde el punto de vista de la racionalidad de la acción, sea sensata, Roxin intenta explicar la utilidad que podría subyacer a la dogmática jurídico-penal y no intenta -salvo con su indeterminado recurso a la posibilidad del "pensamiento sistemático"- reconstruir la cuestión desde el punto de vista de la racionalidad del

\footnotetext{
${ }^{1}$ El ámbito central en el que la racionalidad ha sido tradicionalmente discutida en su posibilidad, por oposición a la ciencia y en general a la racionalidad especulativa, ha sido en la ética. Sobre el particular, ver por ejemplo, las lecciones sobre teorías de la verdad de Jürgen Habermas, en Teoría de la Acción Comunicativa: Complementos y Estudios Previos, Cátedra, Madrid 2001, pp. 94 ss.; Habermas, Jürgen: Teoría de la Acción Comunicativa, Tomo I, Racionalidad de la Acción y Racionalización Social, Taurus, Madrid 2003, pp. 38-40.

${ }^{2}$ Sobre el concepto de racionalidad de la acción como recurso metodológico de la sociología (y una comparación breve con la racionalidad científica), cfr. Weber, Max, Economía y Sociedad, Fondo de Cultura Económica, México D.F. 1964, pp. 6-7. Sobre la diferencia intuitiva entre ambos tipos de racionalidad, Habermas, Jürgen: Teoría de la Acción Comunicativa, Tomo I... (nota 1), pp. 24 ss., y sobre su reconstrucción común en términos de racionalidad comunicativa, de forma crítica en relación con el concepto de racionalidad weberiano, pp. 359 ss. En términos generales, sobre la función de la dogmática, ver Luhmann, Niklas: Sistema Jurídico y Dogmática Jurídica, Centro de Estudios Constitucionales, Madrid 1983, pp. 29-33.

3 Roxin, Claus: Derecho Penal Parte General, Tomo I, Fundamentos y Estructura de la Teoría del Delito. Editorial Civitas 1997, pp. 206-210. Citando a Zaczyk y en términos menos instrumentales y más elegantes, Silva Sánchez, José María, señala que la función de la dogmática penal es hacer una "aportación propia a la realización del derecho justo", en Tiempos de Derecho Penal, Euro Editores S.R.L., Buenos Aires 2009. Aunque el vínculo con la idea de "justicia" pone en duda que una reconstrucción de ese tipo pueda ser tratada como una cuestión de racionalidad de la acción al igual que en Roxin, y puede permitir una reconstrucción de sus pretensiones pragmáticas ilocucionarias, la fórmula es voluntariamente demasiado vaga para servir a ello.
} 
saber, esto es, desde el punto de vista de la pretensiones de corrección en el razonamiento dogmático y de su evaluación. ${ }^{4}$

No nos interesa, en este contexto, entregar un modelo completo de evaluación de la racionalidad dogmática. Antes, este estudio la supone en vez de demostrarla. Lo anterior se funda, al menos, en una constatación de su comportamiento pragmático: no es difícil dar por sentado que la dogmática jurídica, como disciplina, se comporta de un modo análogo a las ciencias naturales. $\mathrm{Su}$ conformación progresiva en torno a escuelas sumamente similares a las comunidades científicas de las ciencias naturales, sobre todo en el ámbito de la evolución de la teoría del delito durante el siglo XX, denota ya externamente una cierta similitud en su racionalidad elitista sociológica. ${ }^{5}$ Así, en la descripción histórica de la teoría del delito, se presenta normalmente una descripción de los programas dominantes (paradigmas de un momento dado) que no varía mucho de autor en autor. En esta clasificación de escuelas, se suele distinguir entre la clásica o causalista; el neo-causalismo; el finalismo; y, finalmente, el postfinalismo, caracterizado de forma distinta por las escuelas actuales. ${ }^{6}$

Pues bien, en la crisis del finalismo que produjo la aceptación progresiva de otros programas como dominantes, un grupo de anomalías relevantes se agrupaban en torno a la teoría de la causalidad. En ésta, varios conjuntos de casos

\footnotetext{
${ }^{4}$ No prejuzgo con ello que en una institución como la dogmática, no existan vínculos directos entre la función que ésta puede pretender cumplir y su racionalidad científica. En un campo artificial como la dogmática, es evidente que hay reflexividad y conexión entre ambas. Sí entiendo, en cambio, que ambas dimensiones pueden diferenciarse a efectos de su análisis: el análisis del razonamiento dogmático y del conocimiento dogmático es diferenciable del análisis de su función. De no serlo, sería indiferenciable de la sociología.

5 Puede resultar llamativa la aceptación de racionalidad científica en la dogmática a base de una cuestión puramente sociológica. Asimismo, puede resultar llamativo que ello se diferencie de la cuestión sociológica general de la racionalidad funcional de la dogmática, la que dejamos fuera del ámbito de lo que nos interesa. La razón es simple. Las ciencias manifiestan al menos dos tipos de racionalidad: una racionalidad en sus pretensiones ilocucionarias (verdad en el caso de las ciencias naturales) y una racionalidad en su organización pragmática o funcional. La teoría de las ciencias ha tendido a poner en duda o problematizar el primer tipo de racionalidad, y a concentrarse en el segundo tipo. Este tipo de racionalidad pragmática interna es completamente distinto del problema de la evaluación de sus resultados o de sus contribuciones sociales como útiles o funcionales (y, de ser el caso, presentaría por lo tanto una tercera dimensión racional, a la que apunta Roxin en el pasaje citado), pese a que en general se sostiene que contribuye a ello. En relación con su pretensión de racionalidad entendida como vínculo con la verdad o la corrección, como hemos visto, la evaluación de ésta en la dogmática y la construcción de un modelo de este tipo para ella excede completamente el ámbito de este trabajo. No sucede lo mismo con la segunda dimensión, esto es, con la dimensión de "racionalidad" en la organización y en la evolución pragmática: aceptar su efectividad en el campo dogmático es simple. Esta dimensión es relevante porque, asumida la presuposición de la efectividad de racionalidad interna en términos de conocimientos dogmáticos, es ésta la que permite la utilización del esquema conceptual de la teoría de las ciencias de Kuhn y de Lakatos en la evaluación en cuestión.

${ }^{6}$ Cfr. por ejemplo Roxin, Claus: Derecho Penal... (nota 3), pp. 196 ss.; Silva Sánchez, José María: Tiempos de Derecho... (nota 3), p. 27; Muñoz Conde, Francisco: Introducción al Derecho Penal, Colección Maestros del Derecho Penal, Euro Editores S.R.L., Buenos Aires 2007, pp. 253 ss.
} 
Willenmann - Conocimientos especiales en la dogmática...

presentaban problemas relativos a la posibilidad de excluir la punibilidad de actores que intuitivamente no parecían poder ser imputados por el resultado lesivo. El finalismo, bajo sus presupuestos metodológicos, no pudo construir criterios adecuados de rechazo de esa conclusión más allá de la culpabilidad, e incluso en ésta, y sólo pudo entregar explicaciones ad hoc. ${ }^{7}$ Así, mientras para los casualistas se trataba de un problema de "adecuación" de la teoría de la causalidad, para Welzel los problemas que no era posible filtrar mediante una aplicación correcta de la teoría de la causalidad, podían ser solucionados como problemas de imputación subjetiva. Welzel sostenía que los cursos causales extravagantes suponían que no fuera posible identificar dolo, pese a que el "conocer y querer" fuera evidente en casos como el famoso caso del envío a un paseo por un bosque durante una tormenta. ${ }^{8}$ La identificación de dichas soluciones como insatisfactoriamente ad hoc y regresivas, se hizo evidente.

El nacimiento y afianzamiento de nuevos programas de teoría del delito se produce precisamente por explotación de esa y otras anomalías del finalismo. Dichos programas reformularon y reinsertaron a la imputación al tipo objetivo como categoría fundamental en la discusión de este tipo de problemas. ${ }^{9}$ Con ello, se desarrolló un campo central en la investigación contemporánea ${ }^{10}$, rebasando con mucho su aplicación inicial de puro complemento a la teoría de la causalidad. Con la reformulación manifiesta que sufre en dicho aspecto la teoría del delito surgen, como es natural, otras anomalías importantes, mucho más específicas, en las distintas propuestas de tratamiento del problema y de los demás frentes de investigación que propusieron los nuevos programas.

Este trabajo no pretende tratar de forma integral la confrontación en torno a la aceptación de la imputación objetiva, ni mucho menos proponer soluciones a sus enigmas. Para hacer lo primero, tendría que confrontarse a los nuevos modelos finalistas con algún programa funcionalista. Eso es un trabajo complejo y aún no suficientemente decantado, de historia científica. Hacer lo segundo, supondría hacer ciencia, no analizar ciencia a la luz de la teoría de la ciencia. En cambio, parece de mayor interés y menor alcance evaluar las diferencias de dos programas pretendidamente rivales, pero en lo esencial al menos afines en la aceptación de la relevancia de la imputación objetiva: Roxin y Jakobs. La elección de los programas no pretende tener una finalidad de tratamiento de todas las opiniones centrales actuales en la materia. Antes, se explica exclusivamente en base a conocimientos personales.

\footnotetext{
7 Cfr Roxin, Claus: Derecho Penal...(nota 3), pp. 362-364, también Jakobs, Günther, La Imputación Objetiva en el Derecho Penal, Universidad Externado de Colombia, Bogotá, 1998, p. 19.

8 Welzel, Hans: Derecho Penal Alemán, Parte General, Editorial Jurídica de Chile, $11^{\circ}$ Edición 1976, pp. 97 y 98.

${ }^{9} \mathrm{Al}$ respecto, para una descripción histórica detallada que excede el marco de interés del trabajo: Frisch, Wolfgang: "La Imputación Objetiva, Estado de la Cuestión”, en varios autores Sobre el Estado de la Teoría del Delito, Civitas, Madrid 2000, pp. 22-31.

10 Así por ejemplo Jakobs, Günther: "La Idea de la Normativización en la Dogmática JurídicoPenal”, en del mismo Sobre la Normativización de la Dogmática Penal, Civitas, Madrid 2003, p. 39.
} 
En aspectos relevantes, como se verá más adelante, los programas de investigación de Roxin y Jakobs son similares. Pero aun cuando parte de la estructura de ambas teorías de imputación objetiva tengan similitudes, ciertas cuestiones específicas conflictivas son resueltas de modo muy disímil. La consideración/exclusión de los conocimientos especiales del autor, dentro del tipo y como problema de imputación objetiva, será el centro del análisis.

En términos simples, y como introducción a la polémica, puede decirse que Roxin diferencia el tratamiento del problema en el ámbito del dolo y de la imprudencia, pese a llegar al mismo resultado. El saber especial del autor debería incorporarse dentro del juicio de prognosis objetivo-posterior en los delitos dolosos ${ }^{11}$ para delimitar el suceso, por ejemplo, del riesgo permitido, mientras que en la polémica sobre capacidades especiales en los delitos imprudentes, Roxin plantea la "solución materialmente correcta" como "generalizar hacia arriba e individualizar hacia abajo" 12 , es decir excluir en el ámbito de la culpabilidad la punibilidad del autor que comete un delito imprudente sólo porque estaría fuera de sus capacidades el evitarlo, y castigar a quien no evita un delito que conforme a sus capacidades y conocimientos podría haber evitado, equiparando las capacidades especiales a los conocimientos especiales. Con ello, llega a una inclusión casi absoluta de los conocimientos especiales en el saber del adjudicador.

Para Jakobs, en cambio, si bien ciertamente el problema de los conocimientos especiales suele presentarse con más frecuencia en los delitos imprudentes, la distinción sería inaplicable. Los conocimientos que el adjudicador debe tener en cuenta no dependerían de la configuración individual del autor, sino de las expectativas relativas al rol que éste represente. Como tal, sería irrelevante que se impute un delito doloso o imprudente: la consideración, según Jakobs, debiera ser la misma. Sólo en ocasiones especiales de responsabilidad por organización, en delitos de responsabilidad por institución y cuando el autor introduce por propia iniciativa los conocimientos especiales en la relación con la victima, incorporándose el conocimiento especial en el rol del autor, pasarían éstos a ser parte del saber del adjudicador para interpretar la situación. ${ }^{13}$

El diálogo directo de ambas propuestas, al respecto, no es muy fluido. Mientras Roxin presenta de extraña forma a Jakobs como representante de la concepción "individualizadora", cuando actualmente es mucho más generalizador que individualizador ${ }^{14}$; la construcción de Jakobs es plenamente autoconfirmatoria

\footnotetext{
${ }^{11}$ Roxin, Claus: Derecho Penal... (nota 3), p. 367.

${ }^{12}$ Ibid., p. 1015.

${ }^{13}$ Jakobs, Günther: Derecho Penal Parte General. Fundamentos y Teoría de la Imputación, Marcial Pons, Madrid, 1997, pp. 252 y 253.

${ }^{14}$ Jakobs, por cierto, se presentaba como "individualizador" en el juicio sobre imputación subjetiva de imprudencia en el año '74. Pese a lo anterior, hacer extensivo esto temporalmente y presentarlo como realidad actual y, sobre todo, afirmarlo respecto del juicio de imputación objetiva, es errado.
} 
Willenmann - Conocimientos especiales en la dogmática...

y autorreferente, por lo que en general no toma mucho en cuenta las críticas. Así, las posibilidades de evaluar directamente ambas teorías, en relación con su construcción o con su solución, sólo pueden ser de consistencia interna directa o de justicia intuitiva. Por lo mismo, en principio sólo una evaluación ciega.

Para proceder a una evaluación más fina, se presentará, en primer lugar, un resumen del esquema conceptual a utilizar. Posteriormente, se realizará una identificación breve de la estructura de los dos programas de teoría del delito, en términos de la teoría de la ciencia, que será seguida por una descripción consecuencial y explicativa de sus propuestas en el enigma reseñado, evaluando en términos internos, en lo posible de historia interna, ambas propuestas.

La tesis central que subyace a este artículo, y que espero se vea demostrada al poder clarificar las razones de las conclusiones y de las diferencias entre éstas, es que el esquema de análisis dado por la teoría de las ciencias permite entender de forma particularmente clara la forma en que funcionan los programas dogmáticos y las confrontaciones en relación con las anomalías que presentan.

\section{Esquema conceptual}

Para los efectos de efectuar la evaluación reseñada, el esquema que se utilizará será casi exclusivamente el sistema conceptual diseñado por Imre Lakatos, en La metodologia de los programas de investigación cientifica. ${ }^{15}$

Para Lakatos, los programas de investigación científica se estructuran contraponiendo dos elementos. En primer lugar, los programas científicos incluyen un "núcleo firme" -también denominado heurística negativa-, constituido por los enunciados base invariables de la teoría, los que le otorgan su identidad a ésta y que por lo mismo son asumidos como infalseables. Por otro lado, los programas de investigación incluyen un cinturón protector de enunciados derivados del núcleo firme -a su vez denominado heurística positiva-, que sí se encuentran sometidos a análisis y a competencia con teorías rivales. Aunque las contribuciones y cuestiones centrales de la ciencia se formulan en la heurística negativa, la ciencia normal se hace respecto del cinturón protector.

En lo que nos interesa a nosotros, es importante clarificar lo que corresponde al núcleo firme de un programa dogmático, el cual no puede ser igual al de un programa de investigación científica, sobre todo porque no puede ser plenamente invariable ni puede guiar matemáticamente o de modo preciso todo el desarrollo ulterior del programa. La noción de heurística negativa de Lakatos se desarrolla principalmente como un análisis del programa newtoniano, su

Pese a ello, Roxin lo cita correctamente como “el” representante de la exclusión de la consideración de los conocimientos especiales, lo que es en general correcto.

${ }^{15}$ Lakatos, Imre: La metodología de los programas de investigación científica, Alianza, Madrid 1993. 
preferencia histórica personal, respecto del cual considera que el núcleo firme se encuentra constituido por las tres leyes de la dinámica y la ley de la gravitación ${ }^{16}$, extendiéndose con más dificultades a posteriori.

En los programas dogmáticos, en cambio, los componentes del núcleo firme no pueden tener precisión matemática, por lo que éstos suelen reformularse sucesivamente, sin necesidad de llevar a ningún cambio drástico. Esto es impensable en el programa newtoniano: las leyes de la dinámica y de la gravitación siempre van a permanecer configuradas del mismo modo. Por cierto puede pensarse en formulaciones distintas, pero son siempre exactamente equivalentes a las formulaciones anteriores, a diferencia de los núcleos firmes de programas dogmáticos, que pueden incluir elementos nuevos en un componente ya fijo u omitir elementos incorporados a dicho componente en formulaciones anteriores.

También es importante clarificar que, mientras el núcleo firme de un programa de investigación físico puede tener componentes bien delimitados y absolutamente identificables, el núcleo firme de un programa dogmático nunca se configura de ese modo. Así, por ejemplo, mientras Lakatos identifica cuatro componentes en el programa de Newton, y cinco componentes igualmente delimitables en el de Bohr ${ }^{17}$, es imposible pensar en hacerlo de igual forma en el núcleo firme de un programa dogmático. Éste se constituye por un conjunto de enunciados que se relacionan entre sí como un todo. La distinción de partes en ese todo es siempre, por lo tanto, arbitraria. Por ello, las agrupaciones que se hacen de los enunciados base de un programa dogmático son siempre más o menos artificiales.

Sin embargo, y a pesar de ambas advertencias, la configuración estructural de los programas dogmáticos es similar a la configuración sincrónica de los programas científicos y lo reseñado no se refiere sino a detalles. El núcleo firme ya no está constituido por cuestiones plenamente inmutables, y su capacidad de determinar la heurística positiva no es tan precisa, pero es importante. También guía por completo los ámbitos de investigación en los que debe fijarse el programa, y los ámbitos infalseables que, precisamente por constituir al programa, están resueltos. ${ }^{18}$ Espero que estas aseveraciones se vean confirmadas al final de este artículo.

En la dogmática, la heurística negativa de un programa suele contener sus enunciados generales de filosofía moral, que guían su producción estrictamente dogmática y los presupuestos fundamentales y metodológicos de desarrollo heurístico. Estos presupuestos guían a su vez todas las aplicaciones pretendidas de los programas dogmáticos y, como veremos, se caracterizan por ser infalseables. No toda directriz metodológica de un programa dogmático forma parte de su

\footnotetext{
16 Ibid., p. 67.

${ }^{17}$ Ibid., p. 77.

18 Ibid., p. 65.
} 
Willenmann - Conocimientos especiales en la dogmática...

núcleo firme. Sólo lo hacen aquellas que, por decisión metodológica, se asumen como infalseables por el programa. De esta forma, lo que distingue al núcleo firme y a su cinturón protector no es necesariamente su nivel de abstracción, ni siquiera su campo de aplicación, sino su infalseabilidad. Esto lo asume el propio Lakatos, al enviar los presupuestos "metafísicos" al cinturón protector. ${ }^{19}$

Al igual que en las ciencias naturales, es difícil pensar que algún programa dogmático acepte como falseada su teoría cuando se discuten sus presupuestos metodológicos fundamentales o sus enunciados centrales de filosofía moral. En general, ni siquiera se toman en cuenta esas críticas; pero cuando se hace, se entregan nuevos argumentos del mismo tipo, usualmente autorreferentes, o simplemente se dice que no se entendió el punto de partida. Esto es una demostración clara del status infalseable de los enunciados base de la dogmática jurídica. En ello, no hay diferencias relevantes -más allá de las reseñadas- con un programa de investigación de las ciencias naturales.

\section{El programa normativista radical de Jakobs}

\section{a) Núcleo firme}

El núcleo firme del programa normativista de Jakobs es complejo, y ha tenido una evolución relevante, contra la consistencia que se le suele atribuir. Desde sus orígenes reconoce la influencia y la aplicación de la teoría de sistemas de Luhmann tanto en aspectos metodológicos como de contenido, lo que se manifiesta de forma más explícita en las primeras formulaciones de su teoría de la pena. Esta influencia ha guiado parte importante de su programa, pese a ser en muchos aspectos sobrevalorada.

\section{a.1. Teoría de la pena}

El primer componente del núcleo firme del programa de Jakobs es su teoría de la pena. Ya desde sus primeras manifestaciones, en "Culpabilidad y Prevención", el fin de la pena se definía por ser la reestabilización de las expectativas normativamente garantizadas, erosionadas por el hecho delictivo que las afecta. Pero, en esta formulación, la pena tendría además manifestaciones físicas o psíquicas esenciales, sobre todo en la ejercitación colectiva en la fidelidad al derecho. La reacción estatal frente a la defraudación de una expectativa normativa sería gravar, además de manera clara, el comportamiento que se imputa con una consecuencia penal, e incrementar las posibilidades de que dicho comportamiento sea en general aprendido como una alternativa de comportamiento inaceptable (...).

\footnotetext{
${ }^{19}$ Ibid., pp. 70 y 71.
} 
Esto es prevención general no en el sentido intimidatorio, sino como ejercicio en la fidelidad hacia el derecho. ${ }^{20}$

Criticando las teorías de la prevención general negativa, Jakobs calificaba la intimidación como una mera consecuencia complementaria posible. Ya en su tratado, Jakobs evoluciona desde su planteamiento inicial diversificando las funciones que le asigna a la pena, las que se manifestarían en tres aspectos diferentes: confirmar la confianza en la vigencia de las normas pese a su infracción; ejercitar en la fidelidad hacia el derecho; y enseñar la conexión entre infracción de las normas y consecuencias por la infracción a los ciudadanos. ${ }^{21}$ Pero a pesar de contener elementos nuevos, el cambio no es particularmente relevante.

Sin embargo, el núcleo firme del programa de Jakobs sufre un cambio de relevancia en 1995, a lo menos en lo relativo a la teoría de la pena, con el replanteamiento que hace en "Sociedad, Norma y Persona". Esta conferencia se desarrolla a partir de la postulación de una de la teoría de la sociedad, en que se la considera como configuración normativa, la que conforma un contexto de comunicación en su interior ${ }^{22}$ compuesto por normas con capacidad de autoestabilización, a través de las poena naturalis y de la incapacidad de adecuación racional del sujeto divergente y de normas sin esa capacidad. Estas últimas, en aquellos casos asumidos como relevantes por los sistemas sociales, corresponden a las expectativas garantizadas normativamente, las que se caracterizan por necesitar de una prestación comunicativa externa para su estabilización, en caso de creación de un orden comunicativo divergente. El Derecho Penal, a través de la pena, realizaría dicha prestación. Por lo anterior, el Derecho Penal y la pena en particular, pero no exclusivamente, serían la respuesta comunicativa que contradice la afirmación comunicativa contradictoria del orden normativo que configura a la sociedad. ${ }^{23}$ La pena pasaría, de esta forma, a ser una cuestión pura de "sentido", reconociendo una influencia hegeliana evidente. ${ }^{24}$ De hecho, y para demostrar el cambio que se produce al interior del núcleo, el mismo Jakobs declara explícitamente fuera de lugar aquellas consideraciones "empíricas" de prevención general positiva que había utilizado en un primer momento:

“(...) la pena (...) significa autocomprobación. Por ello, los estudios empíricos sobre la prevención general positiva han de dar la impresión de estar algo descolocados. Pues afectan al entorno, es decir, a las

\footnotetext{
20 Jakobs, Günther: "Culpabilidad y Prevención", en del mismo Estudios de Derecho Penal, Civitas, Madrid 1997, p. 79.

${ }^{21}$ Jakobs, Günther: Derecho Penal... (nota 13), pp. 18 ss.

22 Jakobs, Günther: "Sociedad, Norma y Persona en una Teoría Funcional del Derecho Penal”, en del mismo Bases para una Teoría Funcional del Derecho Penal, Palestra Editores, Lima 2000, p. 25.

${ }^{23}$ Ibid., p. 20.

${ }^{24}$ Esta consideración de la teoría de la pena ha sido desarrollada en artículos posteriores en que se explicita de forma mucho más directa la influencia hegeliana. Ver, por ejemplo, Jakobs, Günther: "La Pena Estatal: Significado y Finalidad", en del mismo El Fundamento del Sistema Jurídico Penal, ARA Editores, Lima 2005, pp. 40 ss.
} 
Willenmann - Conocimientos especiales en la dogmática...

consecuencias de psicología individual o social, pero no al núcleo de la teoría". 25

Prácticamente la misma calificación que él hiciera en "Culpabilidad y Prevención" a la prevención general negativa, de ser meras consecuencias anexas deseables, la hacía en "Sociedad, Norma y Persona" a una parte de su propia formulación anterior.

\section{a.2. Funcionalización de la dogmática}

El segundo componente del núcleo firme, no menor pese a ser usualmente desconocido, dice relación con la idea de inclusión de la prestación externa de la dogmática en la comprensión interna del sistema jurídico. Jakobs impone como un requisito necesario al desarrollo de todas sus investigaciones el que se hagan a partir de una pretensión funcional. De otra forma, cualquier institución que se cree o se desarrolle sería una institución desarrollada por pura "casualidad".

Por cierto, podría considerarse que no se trataría de un componente original de su programa, sino implícitamente común a todo programa dogmático, que se presenta tras la idea de lo justo ${ }^{26}$ o alguna otra consciencia dogmática general sobre la relevancia de un trabajo de este tipo. El propio Jakobs lo reconoce así. ${ }^{27}$ Pero en su comprensión explícita de la incorporación de la prestación en el desarrollo heurístico, el programa de Jakobs asume una funcionalización evidente y mucho más radical de la dogmática que lo que ésta hace tradicionalmente, y que pretende hacer del Derecho Penal una institución con una complejidad análoga a la sociedad.

Esta funcionalización dogmática no es ciega; al contrario, es completamente autorreferente. La adecuación social se define a partir de la prestación del Derecho Penal a la sociedad, que la define el propio programa al fijar su teoría de la pena. Sin embargo, los problemas de adecuación social se manifiestan en todo el programa y trascienden la consideración exclusiva del merecimiento de pena en virtud de la teoría de la pena, y por ello puede ser útil diferenciar ambos componentes.

\section{a.3. Normativización de sujetos y actores}

El núcleo firme del programa también contiene una comprensión específica de la persona y de la interpretación de su comportamiento. La base de este presupuesto, en su exposición de "Sociedad, Norma y Persona", es que cualquier hecho bruto, tomado de manera aislada, puede ser interpretado de una multiplicidad de formas, sin posibilidad de discriminación. El sentido subjetivo sólo es accesible si se posee

\footnotetext{
${ }^{25}$ Ibid., p. 21.

${ }^{26}$ Al respecto, Luhmann, Niklas: Sistema jurídico... (nota 2), pp. 36 ss.

${ }^{27}$ Ibid., p. 22.
} 
información exhaustiva del sujeto que actúa, lo que falta necesariamente en una sociedad de intercambios anónimos o cuasi-anónimos. ${ }^{28}$ Por lo anterior, el sentido subjetivo no puede ser la base metodológica de interpretación del comportamiento.

En una sociedad con una configuración compleja, la base de la interpretación de los actos debería hacerse a través de la noción de personas. Esta noción debe fijar un ámbito de competencia de forma de poder organizar una sociedad de intercambios complejos. Este principio de comprensión social tiene consecuencias enormes en las aplicaciones pretendidas del programa y lleva a excluir casi cualquier consideración subjetivizante del comportamiento del actor en la construcción de instituciones dogmáticas. Por ello, es esencial sobre todo en el ejercicio que se pretende realizar respecto de los conocimientos especiales.

Desde un punto de partida distinto, Jakobs explica nuevamente el componente anterior en un manuscrito publicado en español sólo en el 2003. "La Idea de la Normativización en la Dogmática Jurídico-Penal" explica la necesidad de normativización de los individuos, hacia una comprensión de "personas", a partir de la diferenciación del contexto cognitivo de comportamiento, en que el individuo se define a partir de "satisfacer o no satisfacer", respecto de una comprensión normativa de la sociedad. Bajo el segundo enfoque, la persona se define precisamente por la imposición de deberes y la titularidad de derechos. ${ }^{29}$ Sólo en virtud de lo que resulte relevante desde esta consideración de persona, se podría proceder a un juicio de imputación individual, es decir, a un juicio de culpabilidad. En ambos estadios, lo central es el juicio de fidelidad al ordenamiento jurídico en tanto persona: como presunción no individualizante antes de la imputación de culpabilidad y como confirmación de la presunción a partir de verificaciones individuales en la culpabilidad.

Ambas formulaciones de la misma idea pueden parecer muy distintas, pero hacen exactamente lo mismo: construir un campo de competencia para la interpretación de los actos de los individuos. Pese a que el primer enfoque se concentre en la posibilidad de interacción y de interpretación de hechos de sujetos anónimos, y el segundo, en la configuración general a través de la fidelidad al ordenamiento jurídico, no son sino distintas formulaciones de la misma idea, esto es, que aunque el juicio de imputación es, en definitiva, un juicio de deslealtad comunicativamente relevante, se trata también de un juicio general sobre lo que la comunidad puede esperar del autor. Esta idea se manifiesta en dos momentos distintos del juicio de imputación de la teoría del delito: la imputación objetiva y la culpabilidad. Con ello, ambas categorías se convierten en las categorías centrales en las investigaciones del programa de Jakobs.

\footnotetext{
28 Ibid., p. 39.

${ }^{29}$ Jakobs, Günther: “La Idea de la Normativización en la Dogmática Jurídico-Penal”, en del mismo Sobre la Normativización de la Dogmática Penal, Civitas, Madrid, 2003, p. 19.
} 
Willenmann - Conocimientos especiales en la dogmática...

\section{b) El cinturón protector}

\section{b.1. Cuestiones generales}

Una evolución a nivel de núcleo firme lleva necesariamente a una reconfiguración del cinturón protector. La medida de la protección, así como la dirección de desarrollo, cambian las condiciones de producción. Por lo anterior, cuando se da un fenómeno raro como un ajuste de importancia de aquello que se asume como infalseable, todo el programa se conmueve, pero esa conmoción se manifiesta con claridad sólo en las áreas del cinturón más directamente influidas por la heurística negativa.

La evolución del cinturón protector del programa de Jakobs, vinculada a la evolución de su núcleo duro, ha pasado de ser una revisión de todas las categorías sistemáticas, y un replanteamiento de la culpabilidad y de la importancia de la imputación objetiva, a ser un replanteamiento de todas las categorías sistemáticas, asumiendo la normativización radical y normativizando todas éstas. Es decir, mientras en un principio el programa sólo buscó reformular dos categorías particulares, y simplemente revisó y corrigió el resto, posteriormente buscó reformular todas las categorías. Esto tiene relación con la radicalización de los planteamientos de la heurística negativa.

El propio Jakobs describe esta evolución como movimiento desde "una corrección normativa (que) va hacia una construcción normativa". Los componentes principales de esta expansión se encuentran fijados de modo invariable en el núcleo firme que, al asumir el desarrollo progresivo del resto del programa, pasan a seguir trabajando en otras áreas desde aquéllas en las que se inició. Sin embargo, la comprensión funcional y normativista del Derecho Penal es compatible tanto con una compresión de puro funcionalismo sociológico-psicológico, como parecía guiarse el programa en un primer momento, como con un programa de comprensión comunicativa de influencia sociológica, pero saturada de consideraciones de sentido ideal. Ello ha llevado a una reconstrucción de ciertas categorías de un modo que no estaba incluido en el núcleo firme original, sobre todo en la fijación de los enunciados que interpretan el sentido comunicacional del acto preciso, es decir en la culpabilidad. ${ }^{31}$

\footnotetext{
${ }^{30}$ Jakobs, Günther: Prólogo a la versión en castellano de Estudios de Derecho Penal, Civitas, Madrid, 1997, p. 7.

${ }^{31}$ La exposición de los componentes específicos de teoría del delito de Jakobs se centrará sólo en los principios heurísticos de mayor importancia y de mayor abstracción, ya que reconstruir un cinturón protector de forma completa podría llevar a reconstruir todas las aplicaciones pretendidas de un programa. Éstas sólo se analizarán sucintamente en lo que sean ilustrativas. Es decir, sólo se expondrá aquello que tenga importancia manifiesta en relación con el debate que cerrará el trabajo, y que constituye su interés o que tenga importancia directa para el programa como todo. En lo primero, lo central es la imputación objetiva.
} 


\section{b.1.1 Normativización de todas las categorías}

La heurística positiva ha evolucionado desde una normativización inicial de los dos ámbitos a los que ha asignado mayor importancia en la construcción de su cinturón -la culpabilidad y la imputación objetiva ${ }^{32}-$ a una normativización extensible a cualquier categoría. Así por ejemplo, en su primer desarrollo la imputación subjetiva no se tematizó a partir de una propuesta de normativización. No fue así particularmente en el ámbito de la imprudencia reseñado con anterioridad. Actualmente, el programa ya ha planteado una propuesta de normativización de esa categoría, en pleno desarrollo. De la misma forma, en materia de autoría y participación, el planteamiento inicial de Jakobs ha evolucionado desde una revisión de la teoría del dominio del hecho a una consideración de "naturalismo" de ésta, para sustituirla por criterios de imputación objetiva. Si bien la mayoría de las categorías normativizadas se encuentran en una primera etapa, imperfecta e incompleta, la evolución del programa ha sido progresiva en este aspecto.

\section{b.1.2 Imputación a falta de fidelidad al ordenamiento jurídico}

Dentro del contexto de los fines de la pena, el juicio preciso que tiene que realizarse al autor es su consideración, o no, por la norma al momento de actuar. La imputación a responsabilidad penal constituye, por lo tanto, siempre un "déficit de fidelidad al ordenamiento jurídico". ${ }^{33}$ Lo que constituye a una persona desde una perspectiva penal es principalmente su capacidad de actuar con fidelidad al ordenamiento jurídico.

Esta idea ha alcanzado tal relevancia en el desarrollo de la heurística del programa de Jakobs, que en junio de 2003 éste afirmó que los conceptos de la dogmática jurídico-penal deben ser construidos con el único fin "de alcanzar un entendimiento acerca de qué es un grado de suficiente fidelidad al ordenamiento jurídico y de cuándo ésta falta". ${ }^{34}$

Así como la imputación a partir de roles encuentra su ámbito de concentración en la categoría de la imputación objetiva, pero se manifiesta en casi todas las categorías que se construyen en términos de teoría del delito, la imputación a falta de fidelidad al ordenamiento jurídico se construye principalmente en la categoría de la culpabilidad. ${ }^{35}$

\footnotetext{
32 La categoría de la acción también conoció una normativización casi coetánea a la de la culpabilidad; pese a ello nunca adquirió la importancia heurística de éstas.

33 Jakobs, Günther: "La Idea de la Normativización..." (nota 29), p. 23.

${ }^{34}$ Jakobs, Günther: Prólogo a Sobre la Normativización... (nota 29), p. 11.

35 Esto, por cierto, no es algo aislado. Los programas funcionalistas siempre tienen como componentes principales de su cinturón protector la culpabilidad y la imputación objetiva, como manifestaciones parcialmente falseables más directas del núcleo. Esto lo distingue, por ejemplo, de otras escuelas que compiten con ellas, como las escuelas analíticas, cuyo centro de atención se expresa antes, por ejemplo, en materia de iter criminis.
} 
Willenmann - Conocimientos especiales en la dogmática...

Existen, sin embargo, diferencias importantes entre ambos juicios. La imputación a partir de roles tiene un carácter notoriamente instrumental, en tanto permite intepretar un material sin sentido excepto para el autor, mientras que las consideraciones de falta de fidelidad al ordenamiento se manifiestan en una voluntad de juicio que excede a la normativización específica. Precisamente por eso se concentran en estas categorías. La primera permite preocuparse de construir una presunción de sentido comunicacional desautorizador, que se da sólo en tanto que se quebrante un rol, mientras que la culpabilidad juzga esa presunción. La falta de fidelidad al ordenamiento permite hacer un juicio de "la planificación de la conducta como fundamento de la imputación", mientras que la determinación de la competencia de la persona, de su rol, permite interpretar lo que se encuentra dentro del ámbito de lo planificable por el autor o de lo que debía planificar, siendo lo demás irrelevante. ${ }^{36}$

Ambas manifestaciones de la normativización se derivan directamente de una necesidad de expansión a partir del núcleo firme, y si se toma como unidad la idea de normativización de categorías y de sujetos, se trata del componente al que el programa le ha asignado mayor relevancia actual. Además, como se verá más adelante, la normativización de la persona para la interpretación del comportamiento bruto es decidora en el conflicto específico del que se ocupa este trabajo.

\section{b.1.3 Deberes positivos y deberes negativos}

Si la persona se constituye principalmente en su rol de sujeto fiel al ordenamiento jurídico, es importante delimitar qué tipos de deberes puede infringir.

Los deberes negativos son los más generales, en tanto se constituyen en relación con derechos de exclusión relativos a la propiedad, entendida como propiedad sobre el cuerpo y sobre las cosas siguiendo la tradición de la filosofía del derecho, establecida entre otros por Kant en La Metafísica de las Costumbres. En este sentido "la propiedad (es) una relación negativa, un derecho a no ser perturbado por los demás" ${ }^{37}$ dentro del ámbito de lo que se tiene. De esta relación que se establece de mutua exclusión entre personas, se deduce el derecho de no perturbar la organización de derechos de terceros y de organizarse, a la vez, de forma que mi organización no lleve a resultados lesivos, arrogándome de esta forma la organización de los otros.

A partir de estos deberes en la organización se deriva el sinalagma entre libertad de organización y responsabilidad por las consecuencias de ésta. Es decir, a un derecho que el ordenamiento le concede a las personas, el de organizarse

\footnotetext{
${ }^{36}$ Cfr. Jakobs, Günther: “La Idea de la Normativización...” (nota 29), p. 38.

${ }^{37}$ Ibid., p. 28.
} 
libremente, le corresponde un deber general de "no lesionar a otros en el curso de tal organización". ${ }^{38}$

Pero además existen deberes con un contenido que no es puramente negativo, sino que incluye componentes de responsabilidad por actuaciones positivas, establecidos en virtud de relaciones especiales, siendo el caso más conocido el de los padres con los hijos. Aquí, la imputación no se limita sólo a arrogarse organizaciones, sino que es una "negación de una ayuda positiva debida". ${ }^{39}$

Esta distinción, como se verá más adelante, tiene algunas consecuencias relevantes en materia de conocimientos especiales.

\section{b.1.4 Culpabilidad}

En la categoría de la culpabilidad se agrupa gran parte de las consideraciones del componente de comprensión de la pena, original y derivado, del núcleo firme. Así, la culpabilidad se caracteriza por ser la instancia de juicio de prevención general positiva. La culpabilidad es el momento de manifestación pura de la teoría de la pena y por ello es el área que sufre la conmoción directa del ajuste de ésta. Lo que se juzga en esta categoría, en general en el programa de Jakobs, es si el autor por su constitución general o por su disposición actual, se encuentra en condiciones de desautorizar a la norma.

En un primer momento, este juicio agrupaba consideraciones de ejercitación en la fidelidad al derecho, lo que desde 1996 se ha diluido por el cambio en el núcleo firme. Ahora, con una comprensión comunicativa de sentido, se trata de discriminar entre "sentido o naturaleza". Mientras el injusto se ocupa de la "presunción de sentido", la culpabilidad, que lo abarca todo, determina finalmente si hay comunicación desautorizadora efectiva o sólo aparente. Esta pretensión de juicio individual no quiere decir que sea subjetiva. Al contrario, la culpabilidad se determina por una medida puramente objetiva, salvo en lo que "no hay que temer un desbordamiento incontrolable". Por ello, lo que se mide en la culpabilidad no "es el sujeto, sino una persona, precisamente la persona más general imaginable, aquélla cuyo rol consiste en respetar el derecho". ${ }^{41}$

La culpabilidad es la categoría en que históricamente ha establecido su centro de confrontaciones el programa de Jakobs.

\footnotetext{
38 Cfr. Jakobs, Günther: “Actuar y Omitir”, en del mismo Sobre la Normativización de la Dogmática Penal, Civitas, Madrid, 2003, p. 101.

${ }^{39}$ Cfr. Jakobs, Günther: "La Idea de la Normativización...” (nota 29), p. 31.

${ }^{40}$ Jakobs, Günther: "Sociedad, Norma y Persona..." (nota 22), p. 43.

41 Ibid., p. 46.
} 
Willenmann - Conocimientos especiales en la dogmática...

\section{b.2 La imputación objetiva}

\section{b.2.1 Cuestiones generales}

La imputación objetiva, como categoría dogmática, se inserta dentro del tipo objetivo, dentro de la "verificación de efectos externos de alguna acción" como algo penalmente relevante. ${ }^{42}$

En sus orígenes, la teoría de la imputación objetiva respondía a necesidades de delimitación racional o funcional en materia de imputación de resultado. Ante la imposibilidad de la teoría de la causalidad de crear criterios idóneos para resolver consistentemente los problemas que se le presentaban en esa labor, los primeros programas posfinalistas, y en particular Roxin, rescataron la categoría de la imputación objetiva para cumplir una labor complementaria a la delimitación de la causalidad. ${ }^{43}$ Pero en su estadio actual, la imputación objetiva excede con mucho su labor original, sobre todo en el programa de Jakobs.

Es importante distinguir en Jakobs dos significados distintos del término imputación objetiva (aunque en realidad son tres). Al igual que los otros programas posfinalistas, Jakobs desarrolló una categoría de la imputación objetiva, pasando a designar con ésta un conjunto de otras instituciones constituidas a su vez por conjuntos de enunciados que cumplen diversas funciones, entre ellas determinar la relación entre acción y resultado como imputable, conservando para estos efectos en parte importante la construcción de Roxin relativa a la creación de un riesgo prohibido y concreción del mismo. Sin embargo, Jakobs también consideraría la imputación objetiva como algo más que una categoría dogmática, a saber, como "un principio social-funcional". ${ }^{44} \mathrm{La}$ imputación objetiva sería un principio o una categoría heurística propia que permitiría interpretar normativamente los hechos, lo que por supuesto engloba su categoría dogmática. Por ello, no sólo se manifiesta en ésta, sino en otras partes del injusto, como en materia de autoría y participación o en las reglas para la determinación de la posición de garante. ${ }^{45}$ Pero su función de principio de interpretación no se agota en ninguna categoría en particular.

Esta consideración de la imputación objetiva como principio heurístico surge, en primer término y casi exclusivamente, de la necesidad de adecuación social del Derecho Penal a la sociedad de la que es vasallo. La respuesta a toda

\footnotetext{
42 Jakobs, Günther: Derecho Penal... (nota 13), pp. 223-224.

${ }^{43}$ La génesis puede rastrearse antes de Roxin, como lo hace Frisch, pero ello no cambia el hecho de que parte de su configuración actual, y la importancia que se le ha dado a la categoría, haya comenzado con propuestas de Roxin.

${ }^{44}$ Jakobs, Günther: "Sociedad, Norma y Persona...” (nota 22), p. 40.

45 Ahora, esta distinción puede saltarse si se consideran los problemas reseñados como problemas de la categoría de la imputación objetiva, rompiéndose la configuración usual de la teoría del delito. Ello puede ser una solución, pero no cambia el hecho de que Jakobs vea en la imputación objetiva algo más que una categoría de teoría del delito.
} 
pregunta de imputación, y sobre todo de imputación objetiva, depende necesariamente del "estadio de desarrollo de la sociedad". ${ }^{46}$

En virtud de la concentración de aspectos de adecuación social, la imputación objetiva lleva a excluir la posibilidad de imputar simplemente por producción de resultados o causalmente de modo naturalista. Hacerlo de otro modo, según Jakobs, asfixiaría la interacción social. Para lograr una teoría de imputación adecuada a la interacción social que se produce en un contexto especifico (la sociedad de intercambios anónimos), se debe recurrir del modo más directo al rol específico que representa cada sujeto en los contextos de comunicación y, en virtud de ello, se fijaría su ámbito de competencia. Es decir, las garantías normativas que el derecho establece no tienen como contenido el que todos intenten evitar todos los daños posibles (si así fuese se produciría una paralización inmediata de la vida social), sino que adscriben a determinadas personas que ocupan ciertas posiciones en el contexto de interacción determinados cometidos, es decir aseguran standards personales, roles que deben ser cumplidos. ${ }^{47}$

Por lo anterior, el marco de interpretación del hecho dañoso dependería exclusivamente de las condiciones del portador del rol y no de la configuración individual del sujeto, ni de su representación o interpretación del hecho. Ello se manifiesta en todas sus aplicaciones pretendidas, pero de forma mucho más clara en materia de imputación objetiva.

La evolución desde las primeras versiones del programa hasta sus estadios más avanzados, particularmente en materia de delitos imprudentes, es relevante. La comprensión de éstos en el marco de las consideraciones individualizantes originales reseñadas pasó a una comprensión puramente, o casi puramente, objetiva: "lo decisivo es que se trata de hechos que producen una perturbación social y no de peculiaridades individuales". ${ }^{48}$ La idea fijada en el núcleo firme desde la elaboración del programa habría pasado a manifestarse sucesivamente en distintos campos de aplicación, llevando a una evolución progresiva en dicha área y que ha tenido atención creciente, pese a que haya declinado en los últimos años.

Así, en resumen, la imputación objetiva como categoría heurística y no exclusivamente en su manifestación dogmático-práctica, sirve precisamente para dotar de "material interpretativo" a un suceso natural, esto es, para determinar su configuración comunicativa precisa y construir una presunción de sentido que se juzga en la culpabilidad. De esta forma, lo que hace precisamente la imputación objetiva es determinar ex ante los ámbitos de responsabilidad que les corresponden a los ciudadanos que se encuentren en la posición del autor.

\footnotetext{
${ }^{46}$ Jakobs, Günther: La Imputación Objetiva... (nota 7), p. 17. Cfr. también Jakobs, Günther: Derecho Penal Parte General... (nota 13), p. 225.

${ }^{47}$ Jakobs, Günther: La Imputación Objetiva... (nota 7), p. 17.

48 Ibid., p. 28.
} 
Willenmann - Conocimientos especiales en la dogmática...

Ahora, en el sistema de reducción de enunciados que constituye a la teoría del delito, dividiremos sus componentes en dos, siguiendo con ciertas desviaciones a Peñaranda, Suárez González y Cancio Meliá. ${ }^{49}$

En primer lugar, Jakobs construye una imputación objetiva del resultado, cuya función es vincular un comportamiento con un resultado lesivo. Esta es la pretensión original de la teoría de la imputación objetiva en su re-introducción contemporánea: servir de sustituto o de complemento, a la ineficaz teoría de la causalidad. Para ello, la imputación objetiva utiliza "la causalidad (como) punto de partida explicativo que es usado como material en bruto en la construcción de sentido normativo; nada más" ${ }^{\prime \prime 0}$, y lo complementa con criterios similares a los creados por Roxin, en lo que se refiere a la imputación objetiva del resultado. Pese a que tienen ciertas diferencias, sobre todo con relación a las consideraciones de cursos causales hipotéticos y alternativos, Jakobs no le ha acordado mucha importancia a este tema.

Pero lo que adquiere relevancia manifiesta, y pasa a ser central en el desarrollo del programa es lo que los traductores de Jakobs llaman imputación objetiva del comportamiento. Es sobre todo este componente de la teoría de la imputación objetiva el que tiene por finalidad entregar el material interpretativo que permitiría otorgarle sentido al comportamiento del autor. Esto se manifiesta en distintas instituciones cuya función es delimitar la competencia por el rol en cuestión. Las principales instituciones que informarían esta labor son el principio de confianza, que permitiría organizar el reparto de tareas en contextos específicos de interacción social; la probibición de regreso, que permitiría delimitar la participación en aquellos casos en que un comportamiento estereotipado es inocuo, permitiendo una organización económica de la sociedad de intercambios anónimos, lo que lleva a imputar el resultado en forma exclusiva a terceros cuya prestación es posterior a la del autor; la competencia de la víctima, es decir, la explicación de la lesión de la víctima como quebrantamiento de su rol y no del imputado; y finalmente el más importante, el riesgo permitido.

\section{b.2.2 El riesgo permitido}

El riesgo permitido es la manifestación más pura de la pretensión de adecuación social de la dogmática. Si se parte de la base de que la vida social asume necesariamente un nivel de riesgos inherentes a la interacción social, fijar los niveles de riesgo que se aceptan es una cuestión que, según Jakobs, dependería de una autodefinición de la sociedad y a la que el derecho habría de adecuarse si se pretende que su labor sea preservar la configuración normativa de ésta. ${ }^{51}$

\footnotetext{
49 Sobre la distinción, ver Enrique Peñaranda Ramos, Carlos J. Suárez González y Manuel Cancio Meliá: "Consideraciones sobre la Teoría de la Imputación de Günther Jakobs", en Estudios de Derecho Penal, Civitas, Madrid 2000, pp. 57 ss.

${ }^{50}$ Cfr. Jakobs, Günther: "La Idea de la Normativización...” (nota 29), p. 39.

51Jakobs, Günther: "La Imputación Objetiva...” (nota 7), p. 48.
} 
Esta formulación corresponde a una pequeña evolución respecto de su tratado, en tanto en éste la referencia a la adecuación social pura no es sino indirecta y se define más bien a través de la teoría de la pena, es decir, a través de su prestación y no del objeto de su prestación. ${ }^{52}$

En cualquier caso, la necesidad de adecuación social que se da directa o indirectamente en la dogmática, tiene como consecuencia que la fijación del ámbito del riesgo permitido no sea una labor jurídica propiamente, sino una labor de legitimación histórica a la que el derecho simplemente "perfilaría". Las normas jurídicas pueden fijar delimitaciones al riesgo permitido, pero ello no puede entenderse sino como "función auxiliar" a la legitimación histórica.

En el caso concreto, la determinación del riesgo permitido en contextos particulares se enmarca en dos ámbitos: ámbitos regulados por normas de peligro abstracto o por alguna norma jurídica, y ámbitos no regulados jurídicamente.

En los ámbitos vitales, en que generalmente hay peligro envuelto que se encuentra regulado ${ }^{53}$, constituiría riesgo permitido lo que defina positivamente como permisos la propia norma de comportamiento que subyace a la norma de peligro abstracto, y no así lo que se encuentre dentro del ámbito negativo de ésta, que fijaría de forma categórica e invariable los comportamientos considerados inadecuados por la sociedad. El riesgo permitido, cuando está regulado a través de normas de peligro abstracto, no se determinaría en virtud del riesgo actual de la actividad. Así, no sería relevante que un campeón mundial de automovilismo tenga posibilidades bajísimas de causar accidentes en la vía al conducir levemente sobre el límite máximo de velocidad y que un principiante que corra justo debajo de éste tenga altas probabilidades de hacerlo. Si no concurren otras circunstancias, y ambos causan un accidente, se le deberían imputar los resultados al primero y, en principio, no al segundo. Además, cuando se define negativamente el riesgo permitido, es decir bajo la forma de "riesgo prohibido", aquello que abarca la norma de peligro abstracto no podría realizarse, ni aun compensando el riesgo con otras medidas de precaución.

En otros ámbitos hay reglas no jurídicas que regulan el riesgo, sobre todo en el ámbito profesional. Además, cuando en un ámbito específico no hay referencia significativa a normas que determinen el comportamiento permitido, el riesgo aceptable se fijaría bajo "el standard de una persona prudente perteneciente al ámbito vital". ${ }^{44}$ En lo que sólo constituye una desviación aparente de la normativización, Jakobs admite consideraciones individualizantes cuando la

\footnotetext{
52 Jakobs, Günther: Derecho Penal... (nota 13), p. 243.

53 Jakobs, Günther, : "La Imputación Objetiva..." (nota 7), pp. 49 y 50. En todo caso, según Jakobs la regulación en los ámbitos regulados no es más que un reconocimiento a la adecuación social de ciertos permisos. La adecuación social informal siempre le precedería.

54 Ibid., p. 52
} 
Willenmann - Conocimientos especiales en la dogmática...

regulación civil de la prudencia exigida pasa debajo del standard corriente. Pero ello no es más que una remisión a otra área regulada, además de ser funcional si se asume que la regulación civil es adecuada socialmente. En todos estos ámbitos no regulados jurídicamente de forma directa, la compensación del riesgo con medidas de precaución idóneas puede dar lugar a un comportamiento ajustado al riesgo permitido.

Por último, el riesgo permitido puede estar configurado de modo positivo. En estos casos, se determinarían normativamente "condiciones ideales" bajo las cuales puede desarrollarse la actividad. La determinación de la permisión no sería categórica como la determinación de la prohibición, por lo que también se presentarían problemas de determinación del riesgo permitido que tendrían que ser solucionados por el adjudicador.

Así, en resumen, los problemas de adecuación social de un comportamiento, en relación con un resultado perjudicial que se produce, no se presentarían en aquellas situaciones en que hay normas que configuran negativamente el riesgo permitido, salvo para determinar si efectivamente se trata del "tipo de comportamiento" definido por la norma prohibitiva, lo que tendría lugar sobre todo si el grado de generalidad de la descripción es tal que no permite determinar nada. En caso de permisiones normativas y de ámbitos no regulados jurídicamente, para la determinación de una situación como cubierta por el riesgo permitido sería necesario recurrir a criterios de imputación imprecisos. Para llevar a cabo esa labor, sería usual decir que se recurre al "juicio de una persona cuidadosa", pero precisamente delimitar los conocimientos y la configuración de esa persona sería, según Jakobs, "la cuestión que dentro del ámbito de la imputación objetiva presenta el mayor grado de dificultad". 55

Entre quienes pretenden objetivar dicha consideración y no hacerla depender de la configuración del causante del resultado, suele sostenerse que el juicio se realiza en base a un observador del hecho que debe estar provisto de "todos los conocimientos de un experto en la materia, y de todos los conocimientos y aptitudes especiales del autor" radicales de la "prognosis objetivo-posterior". Para Jakobs, esta propuesta sería falsa simplemente porque no sería sostenible que existan expectativas sociales de un comportamiento conforme a un estándar como el establecido. Por ello, la configuración del sujeto que realiza el juicio debe ser la "del titular de un rol que en el desempeño del rol pueda realizar la actividad adecuadamente" ${ }^{\text {"57. Dicho titular }}$ de rol podría ser un experto si el rol, en virtud de la actividad desempeñada, lo incorpora. Como se puede ver, esta es una conclusión que se deriva directamente del núcleo firme, en particular, tanto de la definición del criterio diferenciador en

\footnotetext{
55 Ibid., p. 57.

${ }^{56}$ Ibid., p. 61.

${ }^{57}$ Ibid., p. 63.
} 
torno a expectativas sociales, como de la reconducción de éstas a los sujetos delimitados por sus roles.

Pero frente a esta definición surge el problema de los conocimientos especiales, definido por la propia heurística del programa de Jakobs y sin referencia a la problemática general: ¿qué sucede si por conocimientos o aptitudes propias, externas al rol y que no posee el titular habitual, el autor podría evitar el resultado, pero no lo hace? La respuesta intuitiva que se suele dar a esa pregunta es que su acción (u omisión) tiene un disvalor relevante y debe ser castigada. La respuesta de Jakobs es que, casi en todos los casos, ello no podría ser así. La razón es evidente: si no lo exige el rol, no puede exigirse en materia de imputación penal. Pero, en algunos ámbitos, esta cuestión genera un problema relevante a la teoría de Jakobs.

Ésta es la cuestión que en la cuarta parte del presente artículo será explicada y evaluada.

\section{El programa funcionalista político-criminal}

\section{a) El núcleo firme}

El desarrollo del funcionalismo de Roxin, de forma análoga al programa de Jakobs, se opone a una comprensión de la dogmática desligada de su prestación social. En su famosa monografía programática Política Criminal y Sistema de Derecho Penal, Roxin parte de la base de que, bajo una separación fuerte entre política criminal y Derecho Penal como la postulada por Liszt, entre función penal social, la lucha contra el crimen y función liberal y garantista del Estado, no se podrían obtener resultados "materialmente justos", sino simple y ciegamente uniformes e inequívocos, o en términos de Jakobs "consistentemente casuales".

Así, para superar este estadio, el funcionalismo de Roxin pasa a definirse principalmente por referencia a "criterios normativos de política criminal". Ello no significa más que el desarrollo del programa depende de las funciones que el mismo programa le asigna al Derecho Penal. Su objeto externo pasa a configurarlo y definirlo en su programa: "el Derecho Penal es la forma en que las finalidades político-criminales se transforman en módulos de vigencia jurídica". ${ }^{58}$ Por ello, como en cualquier programa funcionalista complejo de dogmática penal, la teoría de la pena define la prestación externa del Derecho Penal y sus categorías de imputación. Ésta, en la concepción de Roxin, cumple funciones preventivogenerales. Así, la pena es entendida como acción comunicativa destinada a evitar la ocurrencia futura de ciertos comportamientos indeseables, funciones preventivoespeciales negativas y, ojalá, positivas. ${ }^{59}$

58 Roxin, Claus. Politica Criminal y Sistema del Derecho Penal, Hammurabi Ediciones, Buenos Aires, 2002, p. 101.

59 Al respecto cfr. Roxin, Claus: Derecho Penal... (nota 3), pp. 95 ss. 
Willenmann - Conocimientos especiales en la dogmática...

Esta construcción de Roxin, "las bases político-criminales de la moderna teoría de los fines de la pena"60, se conforma como la idea central en la estructuración de las categorías dogmáticas de la teoría del delito. A diferencia de Jakobs, este criterio central del núcleo firme prácticamente no ha sufrido alteraciones considerables desde sus primeras exposiciones programáticas de 1970. Ya en su manual, Roxin había planteado la misma idea: defender una cierta comprensión de teoría de la pena y cambiar en virtud de ésta la orientación de la dogmática. También en una conferencia reciente de $2002^{61}$, Roxin presentó como su punto de partida el que "todas las categorías sistemáticas penales se basen en ideas normativas centrales de política criminal". ${ }^{2}$

La idea reseñada más arriba constituye por lejos el componente con más manifestaciones a nivel productivo del programa de Roxin. Comprende además una comprensión cerrada, sin el nivel de autorreferencia de Jakobs, del Derecho Penal. La cita del pie de página 58 incluye, al igual que varios textos programáticos de Jakobs, una definición directa de Derecho Penal, incluyendo la utilización del verbo "ser" para hacerlo ("el Derecho Penal es (...)"). Pero ello no debe llevar a equívoco y equiparar el centro firme con esta pura consideración. De hecho, ni siquiera se trata del principio más general del programa.

Un segundo componente, que raramente se incluye de modo explícito en las consideraciones programáticas de la forma en que se manifiesta el componente anterior, es la referencia a una filosofía moral liberal, y la comprensión del Estado e indirectamente de la sociedad, como distribuidor racional de libertad y autonomía en un contexto de socialidad. ${ }^{63}$ Su adhesión a una concepción práctica tal, difusa y no siempre explicitada, tiene consecuencias muy importantes en la heurística positiva, como se verá más adelante; pero además sirve para una definición un poco más específica del núcleo firme del programa. El vínculo con una filosofía moral y política de corte liberal le permite definir, por ejemplo, las acciones que legítimamente puede efectuar el Estado y, como tal, delimita las posibles políticas criminales que puede llevar a cabo el legislador, más allá de lo que hace el principio de culpabilidad en materia de imputación. Esta idea de una delimitación liberal de las posibles políticas criminales, si se parte como Roxin de la base de que los criterios político-criminales los fija el legislador ${ }^{64}$ y que en ello no interviene el intérprete, tiene consecuencias sumamente relevantes para el programa dogmático. Por ejemplo, este componente del núcleo firme se manifiesta a nivel de aplicaciones pretendidas en la construcción del concepto limitador de

\footnotetext{
${ }^{60}$ Ibid., p. 203.

${ }^{61}$ Cfr. Roxin, Claus: "Normativismo, Política Criminal y Empirismo en la Dogmática Penal”, en del mismo Problemas Actuales de Dogmática Penal, ARA Editores, Lima, 2004.

62 Ibid., p. 55.

${ }^{63}$ Ver por ejemplo: Roxin, Claus: “¿Que puede reprimir penalmente el Estado? Acerca de la Legitimación de las Conminaciones Penales", en del mismo Problemas Actuales de Dogmática Penal, ARA Editores, Lima, 2004, p. 20.

${ }^{64}$ Roxin, Claus: "Normativismo..." (nota 61), p.58.
} 
bien jurídico, una de las bases del cinturón protector y probablemente la única institución a la que su programa le asigna una función esencial y no así el de Jakobs.

Pero la adhesión a una filosofía moral de corte liberal además plantea una segunda comprensión funcional de los fines del Derecho Penal que serían, expresamente, "asegurar las condiciones para una coexistencia pacífica, libre, que respete la igualdad de todos los seres humanos". ${ }^{65}$ Con ello, Roxin reconoce que "la necesidad de intervención estatal y la libertad ciudadana deben ser puestos en un balance armonioso" a través de la dogmática. En ello radica la importancia de la filosofía moral que asume Roxin.

Este componente no varía sustancialmente en sus distintas manifestaciones y sólo adopta formulaciones distintas, pero equivalentes. Siempre exhibe una teoría de la justicia liberal y siempre presenta su programa como el de un Estado social y democrático de derecho, sin importar el contexto de su aplicación. Ello puede encontrar su justificación externa en la Constitución o no, pero es manifestación del Derecho Penal deseable, en lo posible del existente, es decir, a diferencia de Jakobs no es construcción de un Derecho Penal como descripción de una sociedad específica. Para Roxin el Derecho Penal debe ser el de un Estado de derecho, en su comprensión del mismo, mientras que para Jakobs el Derecho Penal es absolutamente contingente a la sociedad en cuestión. ${ }^{66}$

La reacción del programa frente a las críticas al núcleo duro es similar a la de Jakobs. Nunca se asume que siquiera puedan afectarle y las contesta sobreponiendo el núcleo duro a cualquier consideración externa. Así, por ejemplo, en un epílogo a Política Criminal y Sistema de Derecho Penal escrito tres años después de su primera edición, responde a las críticas de Stratenwerth a su criterio orientador de política criminal. Éste le reprocha el que las valoraciones no puedan ser de pura política criminal, ya que ésta asume sólo una racionalidad conforme a fines, y los principios que invoca Roxin pueden ser contrarios a este tipo de racionalidad. Lo que Roxin hace es simplemente repetir su concepción programática de la política criminal: ésta ya debe incluir las valoraciones, y por ello no hay contradicción con el "Derecho Penal". ${ }^{67}$ También en "Normativismo, Política Criminal y Empirismo" responde de la misma forma a la misma crítica. A

\footnotetext{
${ }^{65}$ Roxin, Claus: “¿Que puede reprimir...” (nota 63), p. 20.

${ }^{66}$ Roxin define en repetidas instancias, asimismo, criterios falseadores de teorías. Esto no es propiamente un componente del núcleo firme, pero sí tiene importancia a nivel de todo el programa: lo que no puede hacerse nunca, evidentemente tiene que respetarse siempre. Por supuesto, el primer criterio falseador es autorreferente: una teoría correcta es una teoría que se orienta por criterios político-criminales. También incorpora otros criterios evidentes, como la coherencia, la consistencia, la falta de contradicciones y la orientación conceptual. Pero lo interesante son tres consideraciones distintas: una incorporación de la prestación más directa de la dogmática, su aplicabilidad en la praxis; una referencia directa a criterios empíricos; y tener claridad en la exposición. Por lo menos lo último, y sin necesidad de ningún examen, es evidente que lo cumple. En todo, ver Roxin, Claus: Política Criminal... (nota 58), p. 57.

${ }^{67}$ Cfr. Ibid., p. 109-111.
} 
Willenmann - Conocimientos especiales en la dogmática...

su vez, a la crítica de la posibilidad de una política criminal arbitraria, opone como respuesta el que la política criminal debe ser liberal. Es decir, simplemente combina ambos componentes de su programa. ${ }^{68}$

\section{b) El cinturón protector}

\section{b.1 Cuestiones generales}

Por el orden que tiene la teoría de Roxin, a diferencia de las construcciones diseminadas de Jakobs, la reconstrucción de los componentes relevantes de su cinturón protector puede hacerse de forma mucho más fluida.

El cinturón protector asume metodologías más o menos rígidas para construir sus conceptos y sus teorías que guían sus aplicaciones pretendidas. La idea de Roxin es hacer del cinturón protector una unidad más o menos homogénea en su construcción: identificar problemas dogmáticos (grupos de casos) y, en virtud de las directrices del núcleo duro, "ubicar una idea normativa central" ${ }^{\prime 9}$ que los agrupe. La idea normativa central tendría que confeccionarse con ayuda de los datos empíricos relevantes relativos al grupo de casos y se orientaría político-criminalmente. Lo interesante es que lo central de la idea normativa es que "sirve como tramado con cuya ayuda, a continuación, debe ser revisado todo el material empírico en la medida en que sea relevante bajo el punto de vista de las mismas directivas normativas de decisión". ${ }^{70}$ Este ir y venir de la mirada normativa-empírica es lo que ha llevado a Roxin a autodefinir su método como "normativismo saturado de empirismo", por oposición a la caracterización de Schünemman al programa de Jakobs como "normativismo libre de empirismo". 71

Roxin además incluye en su programa una serie de directrices puramente metodológicas para efectos de la configuración de las categorías específicas en sus relaciones internas. Éstas no se relacionan de modo deductivo -lo que daría lugar a soluciones uniformes pero político-criminalmente incorrectas ${ }^{72}-$ sino con una metodología dialéctica. Ya desde la necesidad de balance inicial entre persecución delictual y libertad ciudadana se manifiesta esta comprensión metodológica: esta contraposición dialéctica se encuentra en la base de su núcleo firme, por lo que se reproduce en todas sus categorías.

Ambas directrices heurísticas generales no fueron incluidas en el núcleo firme, pese a que no es claro que sus componentes no sean verdaderamente infalseables. En particular, los presupuestos metodológicos nadie siquiera los discute y, por lo mismo, pueden asumirse fácilmente como parte del núcleo duro.

\footnotetext{
${ }^{68}$ Roxin, Claus: "Normativismo..." (nota 61), p. 61.

${ }^{69}$ Ibid., pp. 55 y 56.

${ }^{70}$ Ibid., p. 56.

${ }^{71}$ Ibid.

${ }^{72}$ Ver por ejemplo Roxin, Claus: Derecho Penal... (nota 3), pp. 223-225.
} 
Pero su exclusión de esta área tiene por objeto exclusivo el centrar en el núcleo firme sólo consideraciones particularmente productivas y que informen todo el programa y que además sean su verdadero punto de interés en cuanto a reproducción. Las cuestiones metodológicas no son susceptibles de crítica precisamente porque a nadie le interesa el que un concepto se forme efectivamente de manera dialéctica o no, talvez ni siquiera a Roxin. Sí es importante que haya una cierta consistencia en el razonamiento; pero si una aplicación pretendida se deduce de otra en vez de establecerse dialécticamente, de seguro ello será asumido como irrelevante por el programa y por sus contendores.

A partir de estas consideraciones metodológicas, Roxin construye su heurística siguiendo distintos niveles. En primer lugar, identifica una o varias ideas normativas centrales en cada categoría de la teoría del delito, definidas en altos grados de abstracción, y posteriormente confecciona otros criterios más precisos para cada aplicación pretendida en categorías más precisas.

Así, el injusto sería, por oposición a la culpabilidad, un primer estadio de valoración, que tendría por función dirigir conductas a través de normas de comportamiento y normas de sanción, fijando el ámbito de lo prohibido bajo amenaza de sanción. Ello sería una tarea pura de política criminal.

En el ámbito específico del tipo "el criterio diferenciador debe ser la forma en que se han llevado a cabo por el legislador las exigencias del principio nullum crimen sine legem". ${ }^{73}$ Es en el área del tipo donde se plasman las exigencias de prevención general, determinadas a partir del juego entre el principio de legalidad y las formas de tipificación del legislador. La dialéctica adopta esa forma específica en materia de tipo.

En un primer estadio de evolución del programa, la función central del tipo se centraba exclusivamente en la idea del principio de legalidad como rector de la categoría, pero ya en el 2000, en una presentación a la edición que se ha venido citando de Política Criminal y Sistema de Derecho Penal, Roxin le atribuye literalmente a la imputación objetiva una importancia igual a la del principio de legalidad. ${ }^{74} \mathrm{Y}$ ello se manifiesta como una evolución constante: en la citada conferencia de exposición programática del 2002 "Normativismo, Política Criminal y Empirismo en la Dogmática Penal" presenta a la imputación objetiva como el lugar donde se concentra parte importante del enfoque político-criminal en su comprensión del tipo, ya que si el Derecho Penal sólo protege frente a riesgos insoportables, es esencial delimitar en el propio tipo qué riesgo es soportable y cuál no. ${ }^{75}$ Esto, al igual que en la exposición de Jakobs, se desarrollará más adelante. Pero lo importante es ver desde ya que en ambos casos la imputación objetiva es la más evidente manifestación en el injusto de la heurística

\footnotetext{
${ }^{73}$ Roxin, Claus: Política Criminal... (nota 58), p. 61.

${ }^{74}$ Cfr. Ibid., pp. 7-9.

75 Roxin, Claus. "Normativismo..." (nota 61), p. 64.
} 
Willenmann - Conocimientos especiales en la dogmática...

negativa del programa; que en ambos programas su importancia aumenta en el tiempo con el desarrollo de éste; y que en ambos es algo más que una categoría del área del injusto, aunque en Roxin sigue concentrándose en ésta, y en Jakobs no lo haga.

En el área de la antijuridicidad -más bien irrelevante para estos efectos- lo esencial es entender las causas de justificación como colisión de intereses que debe ser solucionada.

Finalmente, la culpabilidad es el área donde se define de manera decisiva si la conducta concreta y no abstractamente general merece de pena. Por lo mismo, se manifiesta en una ponderación pura de merecimiento a la luz de su teoría de los fines de la pena. Probablemente la culpabilidad de Roxin, entre todos los programas de dogmática penal, sea la categoría que incluye de forma más directa la prestación externa como parte de la composición interna del programa. En su primer estadio, en Política Criminal y Sistema de Derecho Penal, esto se engloba totalmente. Allí cualquier cuestión de culpabilidad se reconduce a un juicio de merecimiento político-criminal de pena, aunque ya en esa exposición sugiere utilizar la palabra "responsabilidad". En su manual, lo presenta todo bajo la denominación de "responsabilidad", que pasa a englobar los problemas de "culpabilidad", al igual que en la conferencia del 2002. Pese a ello, reconoce una cierta evolución hacia una dualidad: la categoría de la responsabilidad se compondría de cuestiones puras de "responsabilidad", es decir de ponderación de merecimiento de pena, mientras la culpabilidad debiera ser entendida como test de reprochabilidad personal. ${ }^{76}$ Ambas cosas se relacionan, pero aún en el caso de haber merecimiento político-criminal de pena y no haber "culpabilidad" entendida bajo el prisma del principio de culpabilidad, no podría haber pena. La culpabilidad sería, por ello, un límite a la actuación penal estatal y no en cambio un fundamento necesario a ésta. Estas conclusiones también son manifestaciones puras del núcleo firme del programa.

Posteriormente, en los distintos conjuntos de casos que se integran a las grandes categorías, se construyen otras ideas normativas centrales y se revisa a la luz de estos criterios los datos empíricos.

\section{b.2. La imputación objetiva}

$\mathrm{Al}$ igual que Jakobs, Roxin reconoce en la imputación objetiva algo más que una institución para verificar un vínculo normativo suficiente entre acción y resultado en los delitos de resultado, pero a diferencia de aquél, Roxin concentra su aplicación en la categoría específica. Si bien es cierto que la idea de la imputación objetiva tiene algunas consecuencias fuera de su ámbito categorial (por ejemplo, en el caso de la tentativa), ésta no alcanza a tener esa especie de omnimanifestación en el tipo que sí tiene en el programa de Jakobs.

${ }^{76}$ Ibid., p. 67. 
La base del desarrollo de la teoría de la imputación objetiva sería proporcionar criterios político-criminales adecuados para determinar qué condiciones de producción de un resultado pueden ser vistas como permitidas y cuáles no, pasando estas últimas a ser imputables. Esta es la razón por la que se trata de una categoría que originalmente sustituye o complementa a la causalidad en sus tareas históricas. La necesidad de una configuración tal de la condiciones de imputación de acción a resultado se da justamente porque se reconoce que dicha labor sólo puede ser normativa, ya que la relación empírica a ese respecto, a diferencia de lo que pretendían las escuelas anteriores, no permite determinar nada definitivo. Para ello se configura una teoría de la imputación objetiva en la que lo central es determinar si existe un riesgo creado por el autor, si ese riesgo está efectivamente prohibido, y si es precisamente el riesgo prohibido creado el que se concreta, además de instituciones auxiliares para permitir verificarlo.

Los criterios normativos creados por Roxin, sobre todo en la verificación de la creación de un riesgo prohibido, se construyen a partir de consideraciones de adecuación social, las que en su programa se miden por parámetros políticocriminales. Por ello, por la necesidad de recurrir desde un principio a funcionalidad pura, la categoría pasó a presentarse como tan atractiva para el programa. La extensión de su importancia hacia el resto de la categoría del injusto, equiparándose al gran principio informador de ésta, tiene su origen en dicha idea.

Ello conduce a que en su desarrollo actual, en que se reconoce la importancia heurística crucial de la imputación objetiva, la categoría ha pasado a ser considerada "la columna vertebral del injusto penal", ya que "interpreta la acción típica", proporcionando "un parámetro de interpretación que se orienta de manera inmediata en el injusto material, en la insoportable dañosidad social de la conducta del autor". Como tal, es "una política criminal que trabaja sobre una base empírica, pondera(ndo) intereses de seguridad y de libertad". ${ }^{77}$ Es decir, sería la manifestación práctica directa de los componentes del núcleo del programa y de los conflictos que ya se verifican a ese nivel, esto es, de la relación dialéctica entre interés en la intervención estatal e interés en el ejercicio de la libertad.

En su aplicación práctica, la imputación objetiva supone un test consecutivo que se desarrolla a través de las ideas normativas ya reseñadas, configuradas como estadios sucesivos. Así, sería necesario verificar en primer lugar el vínculo causal empírico, para verificar posteriormente que la acción en cuestión haya creado un riesgo no permitido y finalmente que ese riesgo sea el que se haya concretado en el resultado lesivo.

No habría creación de riesgo prohibido, en primer lugar, en aquellos casos en que según Roxin por lógica no puede haberlo, en particular cuando la acción

\footnotetext{
${ }^{77}$ En todo Ibid., pp. 64 y 65.
} 
Willenmann - Conocimientos especiales en la dogmática...

del autor lleva a una disminución de riesgo. ${ }^{78}$ Tampoco se configuraría creación de riesgo prohibido en aquellas situaciones en que éste no puede considerarse relevante. Finalmente, no habría creación de riesgo prohibido cuando se crea un riesgo que sí es relevante, pero que por consideraciones de adecuación social se considera permitido. Lo interesante es que, pese a que sólo el tercer caso se presente como pura consideración de adecuación social, ya el primero, el pretendidamente lógico, incorpora un criterio de adecuación creado por Roxin, a saber, el supuesto absurdo social de prohibir conductas tales o equipararlas a un conflicto de intereses ${ }^{79}$, y el segundo, pasa a ser difícilmente diferenciable del riesgo permitido, ya que el propio Roxin lo toma de forma explícita como una delimitación de "riesgos socialmente adecuados" o como "conducta socialmente normal y no generalmente no peligrosa". ${ }^{80} \mathrm{La}$ diferencia parece ser, por lo tanto, sólo cuantitativa. En el caso del riesgo permitido, éste es socialmente relevante $a$ priori y, por ello, se presenta como regulado de alguna forma. Esa consideración no se da cuando se habla de falta de creación de riesgo, que por lo tanto requiere de verificación discrecional.

Para la configuración del riesgo permitido, sobre todo en el ámbito de los delitos imprudentes en que la teoría de la imputación tiene una relevancia práctica mayor, se construirían decisiones normativas a partir de conocimientos empíricos. Ello tiene una cierta similitud con el criterio de legitimación histórica de Jakobs, y se asemeja asimismo en los distintos pasos en que este juicio se concreta. En primer término, Roxin señala que se debe recurrir a normas jurídicas, a normas no jurídicas relevantes si faltan las primeras, construyéndose instituciones auxiliares, como el principio de confianza, para precisar lo permitido y recurriendo en forma paulatina a otros criterios. Roxin también incorpora algunos criterios especialmente desechados por Jakobs, como el saldo de costos y beneficios. ${ }^{81}$ Sin embargo, si se comprueba el hecho de que para Roxin el último criterio sólo resulta atendible si no se puede resolver el problema con los otros, mientras que para Jakobs no es un criterio generalmente aplicable, pero puede tener aplicación en ciertas ocasiones dependiendo de la adecuación determinada por éste, se puede comprobar que la discrepancia práctica no es mayor.

Pero sus diferencias son evidentes al evaluar el criterio que en definitiva le permite operar a la institución, esto es, el punto de vista que debe adoptarse para valorar la conducta, y los conocimientos que debe incorporar el adjudicador al hacer el juicio de imputación. Roxin lo considera resuelto bajo la famosa fórmula de la prognosis objetivo-posterior: "el juez debe colocarse posteriormente en el punto de vista de un observador objetivo que juzgue antes del hecho y disponga

\footnotetext{
${ }^{78}$ La idea de poder determinar una disminución de riesgo es, sin embargo, conflictiva. En una importante cantidad de casos, la disminución no es más que sustitución de riesgo. Además, los casos que se tratan como disminución de riesgo por intento fallido de ayuda a la víctima parece más adecuado tratarlos como casos de consentimiento presunto o estado de necesidad.

${ }^{79}$ Ver por ejemplo Roxin, Claus: Derecho Penal... (nota 3), pp. 365-366.

${ }^{80}$ Ibid.

${ }^{81}$ En todo, Ibid., pp. 1.001-1.010.
} 
de los conocimientos de un hombre inteligente del correspondiente sector del tráfico, y además del saber especial del autor”, ${ }^{82}$ es decir, incluye explícitamente los conocimientos especiales. Según puede advertirse, aquí la discrepancia con Jakobs es total.

\section{Conocimientos especiales}

\section{a) Cuestiones generales}

No es casual que la literatura de Jakobs se extienda enormemente en el punto, construyendo distintas instituciones que complementan la idea de adoptar el punto de vista de una persona común en el rol, mientras que Roxin lo considere "resuelto" y casi no haga ajustes específicos para enfrentar el problema de los conocimientos especiales.

Los conocimientos especiales son un problema que se presenta exclusivamente cuando en el juicio de imputación normativa del resultado no se toman en cuenta, a priori, consideraciones subjetivas. Es decir, en aquellas teorías de la imputación objetiva que declaran como irrelevante, por falta de adecuación social, el punto de vista del actor para los efectos de declarar como socialmente inadecuado su comportamiento y, por lo mismo, por lo general (presuntivamente) imputable. En todas aquellas construcciones de baremos de análisis que declaran como exclusivamente relevante el punto de vista del autor o como relevante en conjunto con consideraciones objetivantes, la idea de los "conocimientos especiales" ni siquiera se presenta, es incomprensible e indiferenciable del juicio común de imputación del resultado.

Tratándose de los programas de Roxin y Jakobs, ambos sienten la necesidad de funcionalizar el punto de vista, de hacerlo depender precisamente de lo que esperan sus programas del área del injusto y de eliminar cualquier consideración subjetiva al respecto. Por lo mismo, de entrada se descarta la posibilidad de llevar a cabo un juicio puramente subjetivo que le permitiría al sujeto descuidado estar usualmente dentro de lo permitido. Ello no se correspondería con la competencia que se les atribuye a los sujetos, ni con la necesidad de permitir la interacción en una sociedad de intercambios anónimos; pero tampoco sería político-criminalmente conveniente hacer depender el juicio de la creación de riesgo de la propia conciencia del riesgo del autor. Al menos hacia abajo la cuestión parece sensata, ya que ambos coinciden en que de otra forma se incentivaría la negligencia en la forma de vida.

Pero la gran diferencia radica precisamente en la enorme cantidad de directrices que vienen desde el núcleo firme o que corresponden a principios heurísticos, que Jakobs tiene que respetar para llevar su programa a una

\footnotetext{
82 Ibid., p. 360.
} 
Willenmann - Conocimientos especiales en la dogmática...

normativización consistente. Ya en el núcleo firme de su programa se define la necesidad de normativizar a las personas y desvincularlas de su subjetividad, particularmente en el área de la imputación objetiva. Ello se manifiesta en forma directa en la polémica sobre el punto de vista del observador: Jakobs rechaza de entrada la prognosis objetivo-posterior precisamente por eso. En Roxin no hay constreñimientos de ese tipo. La base del juicio simplemente sería políticocriminal, a partir de criterios de este tipo que el programa fijaría en relación con su teoría de la pena y sólo tendría que respetar el punto de partida liberal. Por lo mismo, lo único que se impone en el área del injusto es una consideración políticocriminal de prevención general, lo que puede traducirse en una idea de imputación a partir de una base amplia como la prognosis objetivo-posterior. Bien es cierto que tanto el núcleo firme como las directrices de desarrollo respecto de la imputación objetiva imponen una necesidad de "ponderación de intereses de seguridad y libertad", y no puede llegar a un baremo tan estricto como el que Jakobs denuncia espantado como un "ampuloso homúnculo del cuidado" 83 en la prognosis objetivo-posterior extrema, esto es, cuando el observador tiene que incorporar todos los conocimientos no sólo del autor sino además del máximo experto en la materia. Precisamente por eso para Roxin el baremo es más bajo, y dota al observador, además de sus conocimientos especiales, de los conocimientos de un hombre inteligente del correspondiente sector del tráfico. ${ }^{84}$ Es decir, sin pasar por construcciones abstractas y estrictas como Jakobs, y sin entrar en el tema de los conocimientos especiales, Roxin llega a una conclusión casi igual a la de aquel, excepto en que pone un estándar de conducta "inteligente" a diferencia del estándar sin valoraciones dado por el "rol".

Tampoco es casual esta coincidencia parcial en la definición abstracta del observador. Ambos programas definen la prestación externa del derecho penal en su propia teoría de la pena y declaran que el derecho penal tiene que ser funcional a la prestación que define el programa, dividiendo posteriormente sus funciones a partir de categorías. Si al tipo le corresponden todas las funciones preventivogenerales en el programa de Roxin, es evidente que ello tiene que desvincularse de una consideración de pura subjetividad. En Jakobs la prestación depende de su propia definición de las expectativas sociales y, como tal, no puede referirse a expectativas individuales ligada a sistemas psíquicos.

Pero el problema de los conocimientos especiales resulta en una anomalía, a lo menos aparente, para ambos, lo que pasará a explicarse.

\section{b) Los conocimientos especiales en la prognosis objetivo-posterior}

Roxin no le otorga demasiada relevancia al problema de los conocimientos especiales; mucho menos, por ejemplo, que al tema vinculado de las capacidades especiales.

\footnotetext{
${ }^{83}$ Jakobs, Günther: La Imputación... (nota 7), p. 59.

${ }^{84}$ Ver por ejemplo Roxin, Claus: Derecho Penal... (nota 3), p. 360.
} 
En la terminología tradicional, los conocimientos especiales son conocimientos que no posee una persona común, y que le permitirían al autor evitar la producción del resultado dañoso. Se ve claramente que, en principio, los conocimientos especiales ya son un problema de subjetividad. Ello implica que su inclusión al parecer va más allá de lo que requiere una perspectiva puramente preventivo-general, con lo que su incorporación incontrovertida en una consideración de tipo objetivo puede resultar sorprendente. Por supuesto, Roxin podría responder a esto en el ámbito de los delitos dolosos comisivos diciendo que tienen que establecerse expectativas generales de que el poseedor de conocimientos especiales no los utilice para dañar a terceros. Excluirlos, y declararlos por lo tanto irrelevantes, no tendría ninguna justificación políticocriminal, ni se deduciría de un planteamiento liberal. Pero, pese que esta respuesta rápida parezca evidente, incluso en los delitos dolosos hay una anomalía, como se mostrará más adelante.

En cambio, en el ámbito de los delitos imprudentes, y esta es la crítica de Jakobs, no puede considerarse en ningún caso una expectativa general de posesión de esos conocimientos que permita evitar riesgos especiales. Es decir, si Roxin renunciara a una continuidad entre delitos dolosos y delitos imprudentes, como por lo demás lo hace en otras áreas, podría salvarse de esas críticas. Pero Roxin no tiene necesidades de hacerlo, ya que su programa no requiere de una diferenciación necesaria en ningún área. Esto porque desde un perspectiva de pura consistencia entre enunciados, no puede considerarse que la idea de incorporar una expectativa de utilización de todos los conocimientos, para no producir accidentes imputables subjetivamente, tenga alguna contradicción con los enunciados de su primer componente del núcleo firme, esto es, respetar los fines político-criminales de la teoría de la pena. Una definición de prevención general tendría que incorporar información empírica al respecto, que seguramente no existe; pero por sentido común puede considerarse que resulta más eficiente incluir una expectativa de utilización de todos los conocimientos, que no incluirla. El margen de flexibilidad que otorga el núcleo firme, por lo menos en lo relativo a los fines políticocriminales de las instituciones dogmáticas, permite hacer una construcción consistente en ambos sentidos en el marco de los delitos imprudentes y no así en los delitos dolosos, donde la consideración de conveniencia político-criminal es mucho más fuerte que la entidad gravamen que impone sobre la libertad la aceptación de su incorporación. Es decir, la idea de los criterios normativos de política criminal no permite solucionar nada en esta área; pero tampoco prejuzga como incorrecta una solución favorable a incluir los conocimientos especiales en la perspectiva del adjudicador.

En cambio, si se toma como punto de partida la consideración liberal y dialéctica del interés en el ejercicio de las libertades, que precisamente se manifiesta en forma directa en el ámbito de la imputación objetiva, la critica de Jakobs tiene posibilidades de interesar al programa de Roxin y puede producir una primera consideración anómala. El interés en el ejercicio de las libertades sí puede soportar 
Willenmann - Conocimientos especiales en la dogmática...

una expectativa de no utilización dolosa de conocimientos especiales para dañar a terceros, pero difícilmente puede considerarse que la adquisición de conocimientos que superan a los que define a una persona habitual del tráfico tenga que significar, para quien adquirió conocimientos superiores, responsabilidades sociales mayores garantizadas con pena. Es cierto que el programa de Roxin es justamente un lugar de ponderación constante entre el interés de intervención y el interés de libertad, que se asume en todo el programa, y que por lo tanto si se considera que los conocimientos especiales deben incorporarse en el ámbito de los delitos imprudentes es porque el propio programa considera que la ponderación se resuelve a favor del interés en la intervención a partir de una reflexión sobre merecimiento de castigo particular. Pero -y ésta es la anomalía- las consideraciones de merecimiento por cuestiones individuales no se hacen en el área del injusto, sino precisamente en la culpabilidad.

Por lo mismo, de este primer componente de la anomalía, que es explotado de forma recurrente por Jakobs en la construcción de su propia solución, surge una segunda anomalía que es mucho más importante. Si, como se ha reseñado, el lugar de ponderación de consideraciones individuales de merecimiento de pena es la culpabilidad, para poder llevar a cabo este juicio individual por consideraciones intuitivas de una prestación social más adecuada, entonces se requiere llevar a cabo un juicio previo afirmativo de imputación objetiva que en cambio no parece ni intuitivo ni consistente con la pretensión de la prognosis objetivo-posterior, y en general con la pretensión de la propia imputación objetiva en sentido amplio. Así, las directivas propias del núcleo duro entran en conflicto con otros principios generales del cinturón protector que se formaron a partir de éstas, como la idea genérica de la imputación objetiva y de la prognosis objetiva. El merecimiento de pena considerado a partir de directrices directas político-criminales y de otras categorías de la construcción programática de sus categorías de teoría del delito, entraría así en conflicto con una institución creada a partir de ello. Un programa sin pretensiones de funcionalismo puede conformarse con eso, por ejemplo en un programa analítico; pero a un programa funcionalista le molesta que la prestación penal entre en conflicto con categorías que se suponen la especifican.

Intentaremos ilustrar esto con el tema paralelo de las capacidades especiales. Aquí no se trata de los conocimientos que puede incorporar el observador o al menos no directamente, sino del baremo que tiene que tenerse en cuenta para imputar a imprudencia. Roxin sostiene que la solución materialmente correcta en el área de las capacidades superiores a la media tiene que resolverse a partir de una idea político-criminal: "evitar lesiones evitables de bienes jurídicos". ${ }^{85}$ Esto sólo podría alcanzarse exigiendo al autor el empleo de todas sus capacidades. Por lo mismo no sería culpable quien no rinde tanto como la figura-baremo (por ejemplo, un conductor con deficiencias motrices), pero sí sería culpable quien podría haber evitado un accidente que no podría haber evitado la figura-baremo (por ejemplo, Michael Schumacher). La anomalía surge porque sin resubjetivar la

${ }^{85}$ Ibid., p. 1.017. 
construcción de la figura baremo -problema de imputación objetiva-, este juicio ni siquiera podría tener lugar como cuestión de culpabilidad.

La anomalía resulta en que si se mantiene la objetividad social en el área de la imputación objetiva, es decir si se mantiene un juicio exclusivamente centrado en lo que puede hacer la figura-baremo, entonces el comportamiento no sería imputable; pero, pese a que dicha respuesta sería consistente con otros enunciados heurísticos, esto no satisface al núcleo firme. La necesidad de separar lo inferior, como juicio de culpabilidad y lo superior, como juicio de injusto no es "un cambio arbitrario de ver las cosas", 86 eso es cierto, pero sí es una anomalía. En la definición del programa ello es un problema de culpabilidad, pero que no llegaría a poder siquiera realizarse cuando se imputa a un sujeto con capacidades de rendimiento superiores a la media si no se hace este ajuste ad hoc. Esa "inarbitrariedad" tiene que interpretarse como una consideración de adecuación social a la luz de la definición de ésta que hace el propio programa. Precisamente, si se trata de un juicio que hace en forma directa el núcleo firme no puede haber arbitrariedad, ya que éste define la adecuación, pero refleja una inconsistencia al interior del programa. La heurística positiva no puede llegar al resultado que el programa considera correcto con las construcciones que ésta ha hecho y, sobre todo, con la interpretación que el programa propone de la gran separación de la teoría del delito entre el injusto y la culpabilidad, funcionalizando ambos pero de una forma más directa la culpabilidad.

En el ámbito de los conocimientos especiales, la construcción es simétrica a la de las capacidades especiales y lleva a una anomalía similar. En los delitos dolosos, esta anomalía se esconde tras la evidencia de la conveniencia políticocriminal y de la adecuación funcional de considerar los conocimientos especiales como incorporados. Es decir, es tan fuerte la consideración de adecuación del resultado, que es difícil percatarse de que haya una anomalía en la construcción. Pero ya en la construcción del delito imprudente, en que la idea de adecuación sólo puede obtenerse a partir de una ponderación complicada que se hace en virtud de condiciones puramente individualizadoras de merecimiento de pena, la anomalía se hace clara. Por lo mismo, el que la anomalía se radique en el área de los delitos imprudentes no se refiere a un problema estructural de éstos (al contrario, la anomalía es justamente estructural del programa y por lo mismo es común a ambos tipos de delitos), sino a que el grado de "desadecuación" en la respuesta que estructuralmente "debiera" derivarse del programa es mucho mayor que en los delitos dolosos.

Ahora, esta conclusión no es simple y probablemente el programa la discutiría como falsa. En virtud de los estándares más flexibles que fija el programa, por lo menos mucho más flexibles que en Jakobs, sería posible contestar que no es necesario concentrar los juicios de merecimiento individual de pena en la culpabilidad, sino que la idea normativa que guía el problema específico

${ }^{86}$ Ibid., p. 1.018. 
Willenmann - Conocimientos especiales en la dogmática...

del área del tipo objetivo (en este caso la prognosis objetivo-posterior) ya puede hacerlo si resulta político-criminalmente necesario. La hipótesis auxiliar del caso, o el ámbito que permite diferenciar la anomalía de un resultado normal, es la presencia o no, de un problema estructural. Y esto debería explotar un programa que pretende competirle. Pero no es mucho lo que puede decirse de su reacción a la crítica. No hay materiales disponibles al respecto y, entre los que tratan el tema, todos llegan a conclusiones similares. El programa, o bien se siente plenamente conforme con su solución a la anomalía, o sólo la trata, estratégicamente, como área de confrontación de menor importancia, por lo que una solución de este tipo es suficiente, pese a no ser del todo correcta.

\section{c) Normativización de la persona, del observador, y exclusión de los conocimientos especiales}

En el programa de Jakobs, la necesidad de crear construcciones específicas que "reparen" la contradicción entre lo que llamaremos resultado directo -es decir el resultado que se deduciría sin estos componentes que se agregan- y adecuación del resultado es mucho más evidente y mucho más ambivalente que en Roxin.

En primer lugar, en virtud de su propia comprensión de la persona en el ámbito de la imputación objetiva y de su configuración de los conocimientos del observador a partir de la figura del portador del rol, Jakobs fija una definición autorreferente de conocimientos especiales: son conocimientos especiales todos aquéllos que están al margen del rol. ${ }^{87}$ En ello se aleja de la disputa doctrinal al respecto, que define los conocimientos especiales como los que no tiene una persona habitual (aspecto en que es, con imprecisión, similar a Jakobs), pero en virtud de los cuales podría evitarse el resultado dañoso.

Jakobs llega a esta definición por parificar como irrelevantes los conocimientos subjetivos que para el resultado son relevantes e irrelevantes. Su comprensión de la persona normativizada, que ya se encuentra en el núcleo firme pero que va adquiriendo especificaciones progresivas en todas las áreas que el programa considera oportunas y entre las cuales la imputación objetiva resalta por sobre todas, tiene que llevar necesariamente a este resultado. En la imputación objetiva, esto es, el área que se preocupa del aspecto externo del delito, de la "presunción de sentido", la persona normativizada se considera en su "rol", en su ámbito de competencia específico y, por tal razón, los conocimientos que se consideran al decidir el caso no pueden ser superiores ni inferiores a los que se esperan de ella. Si para el resultado son relevantes ciertos conocimientos, eso es irrelevante para la imputación objetiva, desde que es ésta, en su consideración normativizada de la persona, la que declara los conocimientos que deben tomarse en cuenta y los que no, con independencia de que el autor no los tenga, o tenga más de lo normal. Por ello, los conocimientos especiales, se trate de un delito

\footnotetext{
${ }^{87}$ Jakobs, Günther: La Imputación... (nota 7), p. 67.
} 
imprudente o de uno doloso, son generalmente excluidos de la configuración del rol a partir del cual se hace el juicio de delimitación.

Desde ya, y antes de pasar a los problemas específicos que enfrenta Jakobs, es importante ver que, con mayor grado de precisión, Jakobs enfrenta exactamente el mismo dilema que Roxin, pero a partir de una autorreferencia. La persona se configura a partir de roles, pero se le tiene que imputar una falta de fidelidad al ordenamiento jurídico. La falta de solidaridad con un resultado que el ordenamiento considera dañoso, al no evitar dolosamente un resultado que podría evitarse sin indiferencia o sin pereza, es perfectamente imputable a falta de fidelidad al ordenamiento jurídico. Pero la construcción de Jakobs intenta respetar en mayor medida las categorías generales del núcleo duro que agrupa en el cinturón protector, y por eso, pese a entrar en contradicción con la adecuación definida desde esa perspectiva, en el cinturón y no en el núcleo, no altera sus construcciones y no incorpora, salvo excepciones, los conocimientos especiales. Por supuesto, el programa considera adecuado el resultado arguyendo que permite un mayor grado de interacción en una sociedad de intercambios anónimos. Pero, pese a ello, el propio Jakobs reconoce buenas razones externas para incluir los conocimientos especiales, aunque termina negándose a hacerlo para respetar sus categorías dogmáticas. ${ }^{88}$

Sin embargo, Jakobs se ve obligado a considerar a los conocimientos especiales en situaciones especiales, que vamos a analizar más adelante. Cuando los incluye, descarta la crítica de tratarse de una anomalía que confunde el lado subjetivo con el lado objetivo del hecho. No se produciría esta confusión, según Jakobs, ya que de lo que se trata es de configurar el "rol del juzgador" y no de la persona en cuestión. ${ }^{89}$ Esta pretensión de superación de la crítica mediante este argumento -poco convincente, formalista, y rayano en la astucia-, también podría haber sido utilizada por Roxin para superar sus propios problemas, pero éste prefiere concentrarse sensatamente en reiterar la conveniencia externa de la solución a intentar convencer retóricamente.

La necesidad de recurrir a criterios normativos de consideración de conocimientos especiales no se da tan solo por mandato de otros componentes del programa, no obstante que Jakobs parece presentarlo así, sino precisamente porque distintos componentes entran en colisión. Jakobs no tiene problemas en descuidar y omitir componentes de posible inadecuación, a diferencia de Roxin, al excluir los conocimientos especiales cuando son problemas menores que además pretende compensar con argumentos externos y con su presentación comunicativa de la sociedad. Ello no sería en ningún caso contrario a su comprensión de la pena. Precisamente por la autorreferencia de la comprensión de su normativismo, en que las prestaciones se definen a su vez en relación con contextos de comunicación

\footnotetext{
${ }^{88}$ Ver por ejemplo Jakobs, Günther: Derecho Penal... (nota 13), p. 251; al considerar que su solución permite aprovechar situaciones de riesgo y manipular resultados.

${ }^{89}$ Ibid., p. 252.
} 
Willenmann - Conocimientos especiales en la dogmática...

que define el propio programa -es decir, el programa define tanto la prestación, la pena, como el objeto al cual se aplica la prestación, la sociedad-, a diferencia de Roxin, es que puede permitirse descuidar ciertas prestaciones imputándolo a adecuación respecto del objeto de la prestación. Pero cuando al programa de Jakobs - a pesar de toda la protección que puede construirse en su cinturón diversificando las consideraciones de adecuación recurriendo a su comprensión de la prestación, o al objeto de la prestación según sea correcto o conveniente- le resulta evidente la inadecuación, cuando ésta es insoportable para la idea de los resultados a los que debiera llevar el programa en su propia comprensión autorreferente definida en su núcleo duro, o incluso cuando lleva a un resultado intuitivamente inaceptable, Jakobs necesita construir criterios normativos que recalifiquen su regla general de exclusión de los conocimientos especiales del ámbito de la imputación objetiva. Y precisamente ahí se radica una anomalía mucho más dura que la que afecta a Roxin, escondida por la posibilidad de resistencia mayor que opone el cinturón protector con un laberinto de referencias cruzadas entre prestación y objeto de la prestación difícilmente franqueable, pero denunciada por la propia aceptación de Jakobs respecto a la inclusión excepcional de los conocimientos especiales.

Pues bien, Jakobs distingue cuatros casos en que pueden presentarse los conocimientos especiales:

i) "El caso normal", en que justamente no se incorporarían al saber del adjudicador los conocimientos especiales del autor. Al respecto, Jakobs utiliza la construcción heurística de diferenciación entre delitos por organización y por competencia institucional. Cuando se trata de simple responsabilidad por organización, es decir de deberes negativos de no arrogación de organización ajena, y no hay ninguna relación que vincule al autor y a la víctima en el sentido de evitar especialmente la producción del resultado, entonces los conocimientos especiales no podrían tenerse en cuenta. La competencia que fija el rol respecto de la relación no implicaría ninguna consideración que permita activar una relación tal, que el autor se vea obligado a usar de todo su saber para evitar la configuración del resultado. Jakobs lo presenta como el caso normal, pero si se miran los ejemplos que da, son casos en los que confluyen elementos mucho más específicos que en las otras categorías. Esto sucede en particular, como se explicará, en el caso del estudiante politécnico que realiza una práctica, y que siguiendo órdenes lleva a cabo una mezcla deficiente de materiales. Aquí, pese a que sabía del error y del posible resultado lesivo consecuente, no se le podría imputar ningún accidente, pues no sería de su competencia. ${ }^{90}$ También lo presenta así en el caso del estudiante de biología que advierte la presencia de una hierba venenosa en una ensalada y que, no obstante, la sirve. ${ }^{91}$ En ambos casos, se superponen competencias personales a competencias derivadas de un ámbito de organización jerarquizado, a diferencia, por ejemplo, del caso del dueño del vehículo que no

\footnotetext{
${ }^{90}$ Ibid.

91 Jakobs, Günther: La Imputación... (nota 7), p. 63.
} 
repara su automóvil, pese a darse cuenta de que tiene ciertas averías. ${ }^{92}$ Por ello, y sobre todo comparando ambos tipos de ejemplos, es difícil ver que se trate del caso usual y que la inclusión de los conocimientos especiales sea sólo excepcional. Además, como se verá a propósito de la cuarta situación, presentar como normal el caso en que no se quiere evitar un daño indeterminado pero no se quiere causar un daño determinado en los delitos dolosos es completamente inverosímil. Una situación de ese tipo es cualquier cosa menos normal.

ii) Sería necesario incluir los conocimientos especiales en delitos por organización cuando pertenece al rol, por una u otra razón, hacer todo lo posible o todo lo necesario ${ }^{93}$ para evitar que se produzca el resultado. Esto puede darse de forma general, con respecto a cualquiera o por la competencia que se autoatribuye el autor en relación con la víctima. El caso que Jakobs repite tanto en su manual como en La Imputación Objetiva en el Derecho Penal es el mismo, en relación con la competencia por el funcionamiento correcto del vehículo del que uno es dueño cuando se advierten averías.

La inclusión de los conocimientos especiales en este ámbito se presenta como variación parcial, en tanto que en su propia comprensión de éstos no son propiamente conocimientos especiales, porque forman parte del rol. Es simplemente una explicitación de una variación con respecto a la comprensión usual de los conocimientos especiales, pero no corresponde a un caso jakobsiano de conocimientos especiales.

La categorización de la diferenciación y la posibilidad de hacer esta diferencia en el caso particular puede resultar muy difícil, lo que realza el carácter ad hoc de la solución. Es difícil ver la diferencia institucional que existe entre un estudiante que realiza experimentos potencialmente lesivos y un propietario de automóviles, más allá de la existencia de una organización jerarquizada. Y ello sólo realza la peculiaridad de la supuesta situación normal. Sin embargo, aún no se trata de una anomalía que sea realmente dolorosa para el programa.

iii) En los delitos definidos por deberes positivos institucionales, formaría siempre parte del rol el incorporar los conocimientos especiales en la relación. Este es el caso más simple y no merece muchos comentarios. La posibilidad de diferenciar el tratamiento entre delitos por organización y delitos por competencia institucional se asume desde los principios más abstractos que guían la formación del cinturón protector como un problema de configuración normativa y no se encuentra con ninguna inconsistencia.

iv) La anomalía evidente que provoca en el programa de Jakobs el tema de los conocimientos especiales se da en el ámbito del dolo. Como delitos que usualmente tienen una configuración de delitos por organización, los

${ }^{92}$ Ibid., p. 65. También ver, por ejemplo, Jakobs, Günther: Derecho Penal... (nota 13), pp. 252 y 253.

93 Ibid., p. 252. 
Willenmann - Conocimientos especiales en la dogmática...

conocimientos especiales debieran excluirse en casi todos los casos a partir de la idea del caso usual (i), si es que no en todos. Jakobs precisamente insiste en esto: es irrelevante para estos efectos la diferencia entre dolo e imprudencia. El tratamiento de los conocimientos especiales no puede diferenciarlos. De esta forma, se respetarían las premisas normativistas respecto de las personas, las que pretenden que en el hecho externo sólo se impute el resultado en relación con la competencia social del portador del rol. Pero esta consideración ya se debilita cuando hay deberes negativos generales o especiales, que constituyen el caso (ii). Y Jakobs además se ve obligado a construir un escenario en que incluso bajo su definición de conocimientos especiales, éstos se incorporarían. Esto sucede cuando el autor, en virtud de sus conocimientos especiales, desvía hacia la víctima un riesgo general, respecto del cual no es competente. ${ }^{44}$ La diferenciación, en el caso del estudiante de biología, se da entre querer matar a una persona específica a la que se odia y, en virtud de ello, servirle el plato envenenado a esa persona específica, o simplemente seguir con el plan y servírsela a quien le correspondía o al azar. En el primer caso sería imputable el homicidio, en el segundo caso no.

El problema es que esto resulta en una diferenciación evidente entre criterios de imputación objetiva a delitos dolosos y a delitos imprudentes. Es muy difícil pensar en un caso en que haya un "conocer y querer" realizar el tipo, bajo cualquier forma de normativización y cognitivización, pero que no se manifieste respecto de una persona determinada, sobre todo desde que se activa por conocimientos especiales. Jakobs lo presenta como la excepción y ni siquiera como exclusividad del ámbito del dolo; pero es claro que el problema de los conocimientos especiales en delitos dolosos no surge cuando el autor no varía un riesgo en virtud de éstos, sino justamente cuando lo hace. Roxin presenta el problema de esta forma y simplifica cualquier crítica, sólo incorporando los conocimientos especiales. La adecuación del resultado esconde la anomalía. En Jakobs, la forma en que plantea el problema esconde la diferenciación del juicio de delitos dolosos e imprudentes, pero lleva a una anomalía de resultado escondida que es muy dura y posteriormente a una anomalía interna. Con ello, por fin se esfuma la fuertemente defendida idea de no distinción entre delitos dolosos e imprudentes.

El proceso es el siguiente: Jakobs prefiere enfrentar en forma directa la anomalía interna que produciría la inclusión de los conocimientos especiales. Para estos efectos, no los incluye nominalmente ni siquiera en delitos dolosos, para así ser consistente con el punto de vista normativista. Sin embargo, Roxin se ve obligado, por la evidencia del fracaso en el resultado, a crear un criterio de incorporación de estos conocimientos al rol, el que finalmente termina convirtiéndose de nuevo en una regla general de imputación objetiva a delitos dolosos que incorpora a los conocimientos especiales. Jakobs prefiere mantenerse aferrado a la idea de la normativización absoluta, a la idea de que las expectativas

\footnotetext{
${ }^{94}$ Jakobs, Günther: La Imputación... (nota 7), p. 66. , formulado con menor precisión en su manual como "introducir por propia iniciativa el conocimiento especial en la relación con la víctima".
} 
no son categóricamente diferenciables en relación con los delitos imprudentes y dolosos, sino sólo en relación con lo que se espera de un rol específico. Este es el origen de su negativa a diferenciar delitos imprudentes y dolosos. Y esto lo lleva a realizar una labor que no puede resolver de modo adecuado, sino sólo esconder su carácter.

El problema en Roxin se reduce a llevar a cabo una construcción que rompe el curso general de la estructura de la teoría del delito que construye su propio programa. Pero la creación de hipótesis auxiliares para defender ese punto no se presenta como particularmente compleja, sobre todo porque sus propias directivas, que privilegian los resultados político-criminales por sobre todo, le dan un amplio margen de respuesta. Además, al optar por la prestación y no por la construcción dogmática interna, se salva de tener que construir excepciones y reglas particulares que hagan aun más complicado el trabajo en el área.

En Jakobs, sus propias construcciones lo asfixian en un área que ha sido históricamente complicada para quienes pretenden hacer desaparecer cualquier subjetivismo del tipo objetivo. La evolución del programa y la fijación de la progresión diacrónica le permitieron omitir pasar por ese test, simplemente revisando el problema en los 70, sin proponer propiamente una normativización. Jakobs no tuvo problemas en ese primer desarrollo en individualizar los baremos de la imprudencia, sin pasar a tratar el problema de los conocimientos especiales antes de normativizar la categoría. Pero la asignación de importancia gradual a la normativización de categorías y personas, idea presente en su propio núcleo duro, con una enorme importancia en la construcción del cinturón protector, le ha obligado a enfrentarse a este problema un tanto extraño sólo desde mediados de los 80 . Y desde ahí son precisamente los componentes superiores del programa los que no le permiten llegar a una solución satisfactoria.

Los conocimientos especiales serían así una anomalía de la idea de normativización, esto es, de la consideración de la persona en relación con la competencia que se le asigna socialmente y no en su individualidad. Si se asume que la sociedad sólo requiere de una prestación comunicativa como la pena cuando hay un hecho con sentido comunicacional y que la presunción de sentido que haga que la sociedad se preocupe del hecho particular sólo puede partir de desbordes del rol, entonces parece ser necesario renunciar a una expectativa general de utilización de todos los conocimientos disponibles para evitar daños, o al menos a una expectativa general de no dañar utilizando conocimientos mayores que los de la media. Esta definición proviene del propio Jakobs. La alternativa a renunciar a esta expectativa es renunciar a la idea misma de la continuidad en la normativización.

Roxin, dentro de los propios constreñimientos de su programa, mucho menores que los de Jakobs, simplemente prefiere afirmar esa expectativa y producir hipótesis auxiliares para no imputar el caso a anomalía. Después de todo, 
Willenmann - Conocimientos especiales en la dogmática...

puede tomarse esta conclusión como un mandato político-criminal, es decir, como consecuencias del mandato supremo de su programa.

Jakobs prefiere no crear una anomalía interna, no considera que existan esas expectativas; pero finalmente se ve obligado a admitir por lo menos una existencia parcial de la segunda. Eso resulta en una imposibilidad de dar verdadera continuidad a la irrelevancia de la diferenciación del dolo y la imprudencia en el tipo objetivo, es decir en una anomalía interna, como en Roxin, pero también en problemas con el resultado que Roxin prefiere salvar.

Por eso, y precisamente por eso, la anomalía resulta mucho más fecunda, mucho más explotable, para los rivales de Jakobs, que para los de Roxin. Pero no es casual, como se dijo desde un principio, que ocurra así. Para el punto de partida normativo radical el problema de los conocimientos especiales no sólo es sumamente complejo de resolver, sino que además tiene una importancia muy superior. No sólo se juega la posibilidad de llevar a cabo la normativización radical que propugna, incluyendo la parificación de las consideraciones objetivas de dolo e imprudencia, reconducibles a una idea normativa de la persona y al desborde de su ámbito de competencia, sino que además se juega la consistencia de sus construcciones normativas con la prestación en relación con las que se constituyen en su origen. Es decir, se juega el que la normativización sea efectivamente funcional y por lo mismo dogmáticamente aceptable. Y en su construcción actual, es evidente que la anomalía no ha sido solucionada.

Por supuesto, ello no debe sobrevalorarse. Tanto en un programa dogmático como en un programa científico una anomalía puede ser persistente y el programa puede ser igualmente persistente en ignorarla. Pese a su insistencia en tratar el tema específicamente, a diferencia de Roxin, Jakobs se ha conformado con una construcción y no la ha cambiado desde que la llevara a cabo. En la evolución entre su manual y la Imputación Objetiva en el Derecho Penal no hay ningún cambio. El programa le asignó una importancia extrema a la normativización absoluta del tipo, trabajando en el área de la imputación objetiva; pero pese a las anomalías resultantes después de ese trabajo interno, ha pasado a tratar otros problemas con mayor fuerza. El programa progresa y a medida que lo hace es normal que surjan anomalías, en las que puede tener que centrarse si son demasiado importantes o a las que pueda ignorar si no las considera decidoras. Esa es la lógica pragmática de las ciencias. Dar por resueltos los problemas, es decir ignorarlos, no es signo en este caso exclusivamente de fracaso, sino al contrario, es signo de que el programa considera que tiene campos más fértiles que atender.

Pero tampoco hay que infravalorar la solución que Jakobs ha propuesto. Es cierto que formalmente provoca problemas, mucho más fuertes que los que le provoca a Roxin. Pero la idea de la normativización radical de la persona es fecunda en el área en la que tiene mayor relevancia práctica, es decir, en el ámbito de los delitos imprudentes. El propio Jakobs lo reconoce, pero lo declara casi un problema estadístico para no renunciar a la unidad subjetiva entre dolo e 
REJ - Revista de Estudios de la Justicia - No 13 - Año 2010

imprudencia que propugna y que no puede alcanzar convenientemente. La definición de los roles otorga una precisión funcional que la idea de la prognosis objetivo-posterior, preocupada sólo de imputar correctamente desde lo absoluto y no de lo exigible y esperable por terceros y la víctima, no tiene. Y pese a que tenga ciertos problemas en delimitar cuando el rol incorpora lo que usualmente se conoce como conocimientos especiales, entrega puntos de partida consistentes y funcionales para no hacerlo. Teniendo en cuenta que los problemas de conocimientos especiales en delitos dolosos casi nunca se presentan, es evidente que la teoría proporciona una propuesta práctica importante. Los problemas son puramente formales, en relación con componentes importantes del programa y con las propias pretensiones que se derivan de éste, pero en la práctica no tienen mayor importancia. 
Willenmann - Conocimientos especiales en la dogmática...

\section{BIBLIOGRAFÍA}

* FRISCH, Wolfgang: "La imputación objetiva, estado de la cuestión”, en VV.AA. "Sobre el Estado de la Teoría del Delito", Civitas, Madrid, 2000.

* HABERMAS, Jürgen: Teoría de la acción comunicativa, Tomo I, Racionalidad de la acción y racionalización social, Taurus, Madrid, 2003.

Teoría de la acción comunicativa: complementos y estudios previos, Cátedra, Madrid, 2001.

* JAKOBS, Günther: La imputación objetiva en Derecho Penal, Universidad Externado de Colombia, Bogotá, 1998.

"La idea de la normativización en la dogmática jurídico-penal", en del mismo Sobre la normativización de la dogmática penal, Civitas, Madrid, 2003.

"Actuar y omitir", en del mismo Sobre la normativización de la dogmática penal, Civitas, Madrid, 2003. 1997.

Derecho Penal. Parte general. Fundamentos y teoría de la imputación, Marcial Pons, Madrid,

“Culpabilidad y prevención”, en del mismo, Estudios de Derecho Penal, Civitas, Madrid, 1997.

"Sociedad, norma y persona en una teoría funcional del Derecho Penal", en del mismo, Bases para una teoría funcional del Derecho Penal, Palestra Editores, Lima, 2000.

"El Principio de Culpabilidad", en del mismo, Bases para una teoría funcional del Derecho Penal, Palestra Editores, Lima, 2000.

"El Delito Imprudente", en del mismo, Bases para una teoría funcional del Derecho Penal, Palestra Editores, Lima, 2000.

"La Pena Estatal: Significado y Finalidad", en del mismo, El fundamento del sistema jurídico penal, ARA Editores, Lima, 2005.

* LAKATOS, Imre: La metodología de los programas de investigación científica, Alianza, Madrid, 1993.

* LuHMANN, Niklas: Sistema jurídico y dogmática jurídica, Centro de Estudios Constitucionales, Madrid, 1983.

* MUÑOZ Conde, Francisco: Introducción al Derecho Penal, Colección Maestros del Derecho Penal, Euro Editores S.R.L., Buenos Aires, 2007.

* PeÑaranda Ramos, Enrique; SUÁREZ González, Carlos J.; y CANCIO Meliá, Manuel: "Consideraciones sobre la Teoría de la Imputación de Günther Jakobs”, en JAKOBS, Günther, Estudios de Derecho Penal, UAM Ediciones, Editorial Civitas, Madrid, 1997.

* ROXIN, Claus: Derecho Penal. Parte General, Tomo I, Fundamentos y estructura de la teoría del delito, Editorial Civitas, Madrid, 1997.

Política criminaly sistema del Derecho Penal, Hammurabi Ediciones, Buenos Aires, 2002.

"Normativismo, política criminal y empirismo en la dogmática penal", en del mismo Problemas actuales de dogmática penal, ARA Editores, Lima, 2004.

“¿Qué puede reprimir penalmente el Estado?”, en del mismo, Problemas actuales de dogmática penal, ARA Editores, Lima, 2004.

"Acerca de la legitimación de las conminaciones penales", en del mismo, Problemas actuales de dogmática penal, ARA Editores, Lima, 2004.

* SILVA Sánchez, José María: Tiempos de Derecho Penal, Euro Editores S.R.L., Buenos Aires, 2009.

* WebER, Max: Economía y sociedad, Fondo de Cultura Económica, México D.F., 1964.

* Welzel, Hans, Derecho Penal alemán, Parte General, Editorial Jurídica de Chile, $11^{\circ}$ Edición, Santiago, 1976. 